\title{
Una mirada a los patrones demográficos de las misiones jesuitas de Paraguay
}

\author{
Robert H. Jackson \\ Texas Faculty Association \\ academicanarchist@hotmail.com \\ Traducción de Jorge Gamboa
}

\begin{abstract}
Resumen
Este artículo analiza la historia demográfica de las misiones jesuitas de Paraguay con el fin de ofrecer nuevas perspectivas basadas en un enfoque comparativo. Se plantea que los patrones demográficos en las misiones guaraníes fueron únicos, lo cual se aprecia al ser comparados con las misiones de otras fronteras de la América española, como la del norte de México. Mientras que las poblaciones nativas disminuyeron en estas misiones, las poblaciones guaraníes se recuperaron y crecieron a través de la reproducción natural, aun después de una severa mortalidad causada por las epidemias. Muchos pueblos nativos obligados a vivir en las misiones o en otras fronteras españolas de las Américas enfrentaron una virtual extinción biológica y cultural, mientras que los guaraníes siguieron siendo una población viable después de la expulsión de los jesuitas en 1768 y el traspaso de las antiguas misiones durante las tres primeras décadas del siglo XIX.
\end{abstract}

Palabras clave: PARAGUAY, MISIONES JESUITAS, SIGLO XVIII, DEMOGRAFÍA HISTÓRICA, MÉXICO.

\section{Abstract}

This essay outlines the demographic history of the Jesuit missions of Paraguay, offering new insights based on a comparative approach. It argues that demographic patterns in the Guarani missions were unique, when compared to missions on other frontiers in Spanish America, such as the north Mexican frontier. While native populations declined on the missions as a result of epidemics, chronic ailments, and other factors, the Guarani populations on the missions generally recovered and grew through natural reproduction even following severe epidemic mortality. Many native peoples brought to live on missions on other Spanish frontiers in the Americas faced virtual cultural and biological extinction, whereas the Guarani remained a viable population following the expulsion
\end{abstract}


of the Jesuits in 1768, and the demise of the ex-missions in the first three decades of the nineteenth century.

Key words: PARAGUAY, JESUIT MISSIONS, $18^{\mathrm{TH}}$ CENTURY, HISTORICAL DEMOGRAPHY, MEXICO.

Rousseau, Roland Jaffe y los hermanos Berrigan comparten un interés e incluso una obsesión por las misiones jesuitas ubicadas en la región que llamo el Gran Paraguay (partes de Paraguay, Argentina y Brasil), aunque sus intereses fueron al mismo tiempo bastante diferentes. En su novela Cándido, Rousseau ubicó su protagonista en una versión exagerada e idealizada de una utopía semejante a una misión. Jaffe y los hermanos Berrigan colaboraron en 1986 en la película de Hollywood, La Misión, que se basó en los hechos que rodearon la Guerra Guaraní de mediados de la década de 1750 e involucraron a las misiones.

Las misiones jesuitas de Paraguay han cautivado y capturado la atención y el interés popular y académico por más de dos siglos. Sin embargo, aún existen muchas cosas desconocidas sobre su historia, en particular sobre la experiencia de los guaraníes que vivieron allí. Ha habido avances significativos en el estudio de las misiones en años recientes, particularmente en las áreas de la historia sociocultural ${ }^{1}$. Pero un aspecto que no ha sido estudiado adecuadamente es el de los patrones demográficos, particularmente a la luz de los recientes avances en el estudio de demografía histórica en cuanto a los métodos, las fuentes y los enfoques comparativos ${ }^{2}$.

Este artículo analiza la historia demográfica de las misiones jesuitas de Paraguay avanzando a partir de los estudios previos, con el fin de ofrecer nuevas perspectivas basadas en un enfoque comparativo que ubica los hallazgos sobre los establecimientos paraguayos dentro del contexto de los patrones de las misiones de la frontera norte de México. Igualmente, empleo el programa de computador llamado Populate, que

1 Véanse, por ejemplo, Arno Alvarez Kern, ed., Arqueologia Historica Missioneira (Porto Alegre: Edipucrs, 1998); Barbara Ganson, The Guarani Under Spanish Rule in the Río de la Plata (Stanford: Stanford University Press, 2003); Rafael Carbonell de Masy, Estrategias de desarrollo rural en los pueblos guaraníes (1609-1767) (Barcelona: Instituto de Cooperación Iberoamericana, 1992); Moacyr Flores, Reduçoes Jesuiticas dos Guaranis (Porto Alegre: Edipucrs, 1997).

2 Varios estudios proporcionan un panorama de los patrones y tendencias demográficas generales. Entre otros, se pueden consultar: Carbonell de Masy, Estrategias; Ernesto Maeder, "La población de las misiones de guaraníes (1641-1682). Reubicación de los pueblos y consecuencias demográficas”, Estudios Ibero-Americanos 15, núm. 1 (junio 1989): 49-80; "Fuentes jesuíticas de información demográfrica misional para los siglos XVll y XVlll”, en Fuentes útiles para los estudios de la población Americana: Simposio del $49^{\circ}$ Congreso Internacional de Americanistas, Quito 1997, coord. Dora Celton (Quito: Abya-Yala, 1997), 45-57; Daniel T. Reff, "The Jesuit Mission Frontier in Comparative Perspective: The Reductions of the Río de la Plata and the Missions of Northwestern Mexico, 1588-1700”, en Contested Ground: Comparative Frontiers on the Northern and Southern Edges of the Spanish Empire, eds. Donna Guy y Thomas Sheridan (Tucson, 1998), 16-31. 
usa la proyección inversa para calcular la esperanza de vida promedio al nacer. Esta esperanza promedio de vida muestra qué tanto vivía una persona promedio en las comunidades misioneras de Paraguay, lo cual a su vez puede ser usado para hacer comparaciones con la esperanza de vida de las poblaciones europeas contemporáneas y las de las misiones de la frontera mexicana ${ }^{3}$. Se plantea que los patrones demográficos en las misiones guaraníes fueron únicos, lo cual se aprecia al ser comparados con las misiones de otros lugares de la América española, como la frontera norte mexicana. Mientras las poblaciones nativas disminuyeron en estas misiones como resultado de las epidemias, las enfermedades crónicas y otros factores, las poblaciones guaraníes de las misiones se recuperaron generalmente y crecieron a través de la reproducción natural, aún después de una severa mortalidad causada por las epidemias. Muchos pueblos nativos obligados a vivir en las misiones o en otras fronteras españolas de las Américas enfrentaron una virtual extinción biológica y cultural, mientras que los guaraníes siguieron siendo una población viable después de la expulsión de los jesuitas en 1768 y el traspaso de las antiguas misiones durante las tres primeras décadas del siglo XIX.

Los guaraníes anteriores al establecimiento de las misiones eran agricultores sedentarios que vivían en un sistema social y político basado en el clan. Muchos fueron también incorporados al sistema de la encomienda por los españoles establecidos en Asunción en 1537, el cual también influyó indirectamente en los líderes de los clanes guaraníes. A diferencia de lo que sucedió en las misiones del norte de México, los jesuitas incorporaron el sistema de clanes a la estructura social y política de las nuevas comunidades misioneras. Los jefes de clan, llamados caciques por los españoles, compartieron el poder con los misioneros dentro de un sistema indirecto. Los caciques mantuvieron el control sobre sus sujetos y gobernaron las comunidades en la misión a través de cabildos. Los documentos de las misiones, como registros de bautismos, defunciones, matrimonios y censos, dan testimonio de la continuidad de la autoridad de los caciques sobre los neófitos. Los censos organizaron a los guaraníes de acuerdo con la jurisdicción de cada cacique, e incluyeron el nombre del cacique de cada comunero en los registros sacramentales. La incorporación del sistema de clanes dentro de las misiones proporcionó una estabilidad y una continuidad que estuvo ausente en otras partes, como en la frontera norte mexicana, donde la congregación en misiones generalmente desorganizó las relaciones sociales, incluyendo los patrones de matrimonio exógeno y las alianzas sociales y políticas entre las comunidades y los pueblos, que proporcionaban acceso a una variedad de géneros.

En este ensayo se analizan primero las fuentes y luego se presenta una revisión cronológica de algunos períodos seleccionados en la historia de las poblaciones de las misiones, sus tasas vitales y la estructura de géneros. La conclusión ofrece algunas reflexiones comparativas.

\footnotetext{
Véase la nota 25.
} 


\section{Fuentes y enfoques}

Dos conjuntos de fuentes se emplean generalmente en los estudios demográficos de poblaciones históricas. Se trata de censos y registros de bautismos, defunciones y matrimonios. Solo algunos fragmentos de dos registros sobreviven en las misiones jesuitas. El primero es una corta serie de bautismos que cubre los años de 1754 hasta 1763 en la misión Santa Rosa, junto con los primeros años del siglo XIX. El segundo es una serie de bautismos y entierros en San Francisco de Borja, que va desde la década de 1790 hasta la segunda década del siglo XIX. Estos registros documentan prácticas sociales y patrones demográficos en el período que sigue a la expulsión de los jesuitas en 1768 y la conquista portuguesa de las siete misiones ubicadas al este del río Uruguay. Por ejemplo, los padres asignados a las antiguas misiones siguieron registrando el cacique de los comuneros guaraníes en los censos y los registros sacramentales.

Los vacíos que se presentan en los registros sacramentales no constituyen un serio problema para el estudio de la demografía histórica de las misiones jesuitas cuando han sobrevivido censos detallados. Hay dos tipos de censos. El primero es la numeración anual que resume las estadísticas vitales de las misiones, incluyendo el tamaño de la población, junto a la cantidad de bautismos y nacimientos, entierros y matrimonios registrados cada año. Estos datos pueden ser usados para reconstruir las tasas brutas de nacimiento y mortalidad, que son indicadores importantes de los cambios que sufre una población a través del tiempo. Sin embargo, los totales anuales de entierros no sirven para documentar adecuadamente la mortalidad causada por las epidemias. En estudios anteriores, en los cuales usé registros de entierros, dividí la cantidad de muertes en totales mensuales, con el fin de identificar más adecuadamente el impacto y la duración de una epidemia. El registro de entierros de San Francisco de Borja mencionado anteriormente documenta una epidemia; he basado mi análisis del brote en un aumento de las muertes mensuales.

Siempre es importante saber el propósito para la preparación de un censo, con el fin de entender las posibles deficiencias en el conteo de la población. Por ejemplo, los hombres jóvenes pueden haberse inclinado por eludir los conteos en un censo preparado para identificar reclutas potenciales para el servicio militar, y los censos con propósitos tributarios, como los que se hicieron en la región andina de Suramérica, son poco confiables, ya que los líderes nativos escondían a los tributarios y muchos optaron por no pagar sus obligaciones tributarias usando sus pies, migrando a las ciudades españolas o a otros pueblos de indios ${ }^{4}$. Los guaraníes también dejaron las misiones, pero un buen número de padrones detallados, como las series de 1735, registraron también a los ausentes, y en épocas tan tardías como la década de 1790 los oficiales del gobierno en las diferentes jurisdicciones de una amplia región contaron a los

4 Véase, por ejemplo, Robert H. Jackson, Regional Markets and Agrarian Transformation in Bolivia: Cochabamba, 1539-1960 (Albuquerque, 1995). 
guaraníes ausentes de las antiguas misiones que encontraban viviendo en los distritos bajo su administración.

Muchos neófitos guaraníes de las misiones llegaron a trabajar para los colonos en Paraguay y fueron contados en los censos de los nativos no pertenecientes a las misiones. También hubo una comunidad de fugitivos guaraníes que fue descrita en un reporte de 1736, ubicada al oeste de las misiones, entre los ríos Mirinay y Corrientes. Esta comunidad, aparentemente organizada en las márgenes de una de las misiones, constaba de 23 hileras de casas distribuidas en bloques según la procedencia de los indios. Una hilera fue asignada a los neófitos de San José, San Cosme, Candelaria, Santa Ana, Trinidad, Corpus Christi, San Ignacio Mini, Mártires y Concepción. Los neófitos de Loreto, Santa María y Apóstoles ocupaban dos hileras de casas. Los de Santo Tomé ocupaban tres hileras y los de La Cruz, ubicados cerca del sitio del poblado, ocupaban dos. Los nativos usaban caballos y se sostenían a sí mismos parcialmente con el rodeo de ganado 5 . Un análisis del tamaño de las poblaciones en las misiones debe tener en cuenta un cierto grado de emigración.

Solo la muerte y los impuestos son inevitables y los gobiernos prepararon muchos censos con propósitos fiscales. Los pueblos nativos que vivían bajo el dominio español pagaban un tributo, incluidos los guaraníes de las misiones de Paraguay. El gobierno español organizó y costeó voluminosos censos tributarios, y algunos de estos recuentos (padrones) han sobrevivido, con abundante información sobre la población de las misiones. Los censos dividen la población teniendo en cuenta los cacicazgos a los que pertenece hasta épocas tan tardías como la década de 1840, más de setenta años después de la expulsión de los jesuitas y el traspaso del control de las misiones a administradores civiles. Los cacicazgos fueron las unidades sociopolíticas dentro de las misiones y los caciques guaraníes fueron los jefes que gobernaron a la población. Los censos también dividen la gente en grupos familiares; el análisis del tamaño de las familias proporciona indicios para comprender las razones por las cuales una población aumenta o disminuye. He analizado varios censos detallados, pero el más valioso de todos es el conteo realizado en 1759 en la misión Corpus Christi 6 . Los jesuitas incluyeron la fecha de nacimiento de cada uno de los residentes en la misión, junto con el lugar de origen de aquellos nacidos en otra parte. Esto permite una reconstrucción confiable de la estructura de edades y géneros de la población en un momento determinado. Además, la información sobre el lugar de origen de los guaraníes proporciona indicios de sus patrones matrimoniales. La gran mayoría de los hombres de Corpus Christi se casaron con mujeres de la misma comunidad, aunque había varias

Rafael Carbonell de Masy, S. J., Teresa Blumers y Norberto Lveinton, La reducción jesuítica de Santos Cosme y Damián: Su historia, su economía y su arquitectura (1633-1797) (Asunción, 2003), 142.

6 "Matricula deste pueblo de Corpus Christi”, Archivo General de la Nación, Buenos Aires, Padrones de Indios, sala 9-17-3-6. 
misiones cercanas con grandes grupos de esposas potenciales. Esto mantuvo la estabilidad social y ayudó a reforzar las buenas relaciones entre los diferentes cacicazgos dentro de cada misión.

Durante el apogeo de las misiones en el siglo XVIII, los jesuitas organizaron las treinta misiones en dos distritos. El primero comprendía las comunidades a ambos lados del río Paraná. Fueron San Ignacio Guazú, La Fe, Santa Rosa, Santiago, Encarnación de Itapúa, Candelaria, San Cosme y Damián, Santa Ana, Loreto, San Ignacio Mini, Corpus Christi, Jesús y Trinidad. El segundo abarcaba aquellas localizadas a ambos lados del río Uruguay. Este grupo incluía San José, San Carlos, Los Santos Apóstoles, Concepción, Santa María La Mayor, San Francisco Javier, Los Santos Mártires de Japón, San Nicolás, San Luis Gonzaga, San Lorenzo Mártir, San Miguel, San Juan Bautista, Santo Ángel Custodio, San Tomé, San Francisco de Borja, La Cruz y Yapeyú.

Finalmente, unas palabras sobre el estado de los tratamientos médicos durante los siglos XVII y XVIII y los métodos usados por los jesuitas para combatir las epidemias. La teoría de los gérmenes no tuvo una aceptación general hasta finales del siglo XIX, y durante el período en que los jesuitas tuvieron las misiones a su cargo se creía que las epidemias eran una maldición o un castigo enviado por Dios, que la enfermedad se originaba en un desbalance en los cuatro humores básicos (tierra, aire, agua y fuego), o que surgía de vapores venenosos llamados miasmas, que se formaban de la vegetación, los cuerpos en descomposición y otros materiales corruptos ${ }^{7}$. La técnica más común usada en Europa en esta época fue la cuarentena, aislando físicamente a los infectados del resto de la población en una casa especial donde los enfermos recibían muy poco o ningún cuidado, con el fin de prevenir que la gente entrara o saliera de sus comunidades cuando se desataba una epidemia. Los jesuitas aplicaron la cuarentena en las misiones separando a los enfermos del resto de la población ${ }^{8}$.

La vacuna de Edward Jenner, descrita por primera vez en una publicación de 1796, no llegó a la América española antes del comienzo del siglo XIX, y durante los siglos XVII y XVIII la viruela fue probablemente el más grande asesino de los pueblos nativos de las Américas. La referencia más temprana acerca del uso de la inoculación por variolación, un tratamiento contra la viruela introducido en Europa en los primeros años del siglo XVIII desde el Medio Oriente, donde su uso tenía una larga historia, se registró en 1796, cuando un doctor establecido en la antigua misión Yapeyú inoculó 126 personas de San Francisco de Borja durante una epidemia de viruelas, de las cuales solamente murieron 15 . El doctor atribuyó estas muertes a otras complicaciones, como una enfermedad venérea que debilitó el sistema inmunológico de los infec-

Acerca de los patrones demográficos europeos contemporáneos y las teorías sobre la enfermedad y los métodos usados para combatir las epidemias, véanse: Michael Flinn, The European Demographic System, 1520-1820 (Baltimore, 1980) y Robert H. Jackson, Indian Population Decline: The Missions of Northwestern New Spain, 1687-1840 (Albuquerque, 1994).

8 Guillermo Furlong Cardiff, S. J., Misiones y sus pueblos de guaraníes (Buenos Aires, 1962), 612. 


\section{Figura 1}

\section{Mapa de las misiones jesuitas de Paraguay}

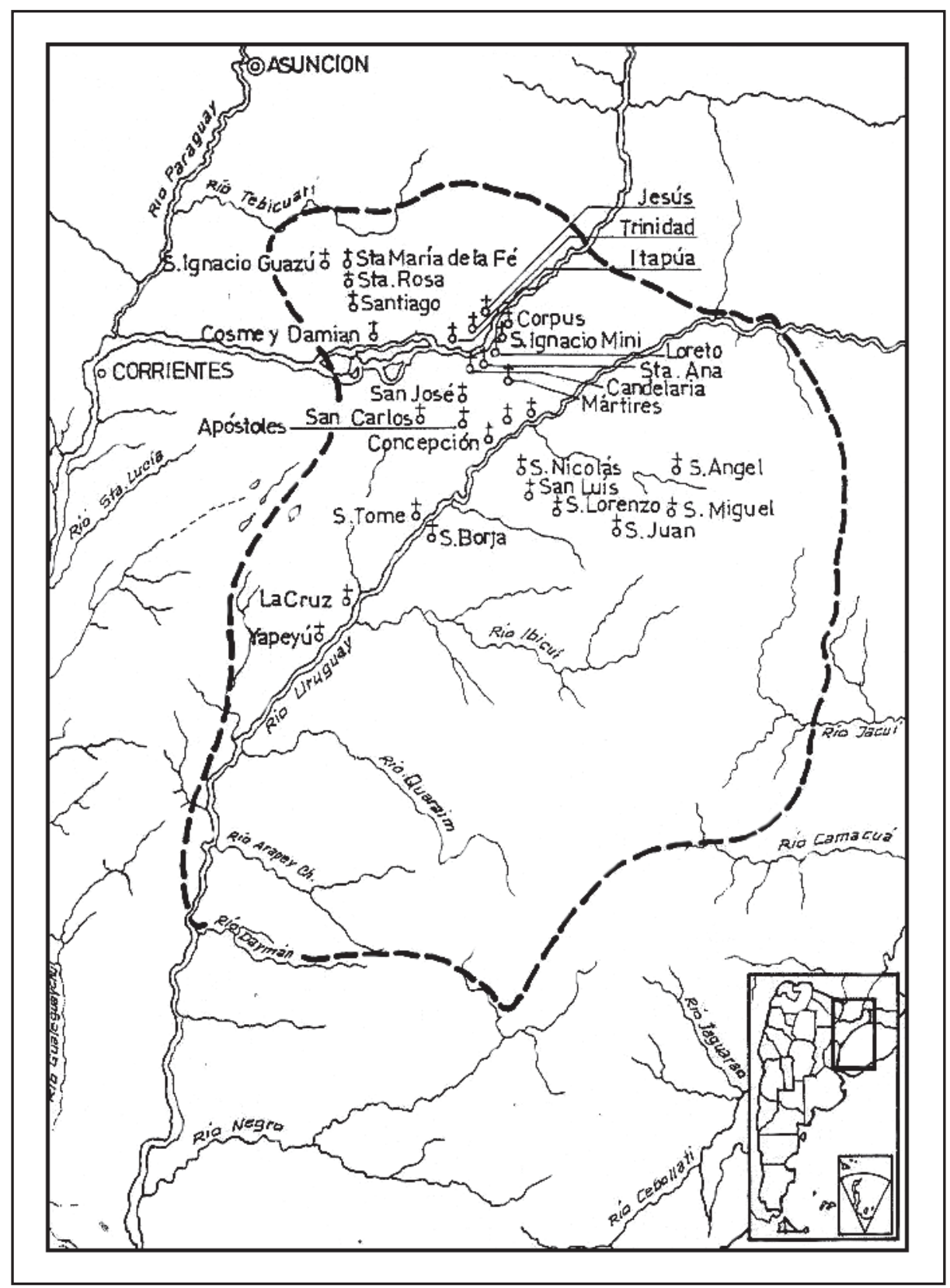

Fuente: Ernesto Maeder, Misiones del Paraguay: Conflictos y disolución de la sociedad guaraní (17681850) (Madrid: Mapfre, 1992). 
tados por la viruela9 . La inoculación por variolación consistía en inyectar pus de una pústula madura de la piel de una víctima de la viruela en el cuerpo de un individuo sano, con la esperanza de que la infección resultante fuera muy leve. Sin embargo, las viruelas fueron una enfermedad tan aterradora que hubo una gran resistencia popular a este procedimiento, que se percibía como una forma de diseminar el contagio. El gobierno español distribuyó información sobre esta técnica a través de toda la América española en las últimas décadas del siglo XVIII. Los médicos usaron por primera vez el procedimiento en la ciudad de México durante una epidemia en 1779, y dos años después, una vez que el contagio se extendió hacia el norte hasta las misiones de la frontera, algunos religiosos dominicos de baja California inocularon a los neófitos de sus misiones. Las tasas de mortalidad en los lugares donde estos habían sido inoculados fueron mucho más bajas que en las misiones vecinas, donde los nativos permanecieron desprotegidos ${ }^{10}$. Era muy poco lo que podían hacer los jesuitas para proteger a los neófitos guaraníes de las epidemias periódicas, y la ineficacia del tratamiento en las misiones se puede medir por la gran cantidad de muertes que se presentaban.

\section{El período español temprano, hasta 1609}

El primer intento español para colonizar la región del Río de la Plata se hizo en la década de 1530. Un esfuerzo fallido para establecer una comunidad en Buenos Aires fue seguido por un éxodo hacia el interior y el establecimiento de Asunción, en 1537, en tierras guaraníes. Los académicos entran frecuentemente en lo que he llamado "el juego de los números", que consiste en una serie de esfuerzos para hacer estimaciones sustentadas acerca del tamaño de las poblaciones nativas al momento del primer contacto y el grado de disminución desde este hasta la época en que las autoridades civiles o religiosas midieron el tamaño de las poblaciones bajo el dominio español. Los investigadores han sugerido que la población guaraní era por lo menos de 1.000.000 de personas cuando los españoles llegaron al Río de la Plata, en la década de 1530, y que disminuyó hasta 141.000 durante los primeros años de la década de $1730^{11}$. Además, Reff ha planteado que a finales de la década de 1630 por lo menos dos tercios de los guaraníes fueron capturados por los bandeirantes, traficantes de esclavos de Sao Paulo ${ }^{12}$.

Las epidemias se desataron periódicamente dentro de las poblaciones guaraníes después de la llegada de los españoles en la década de 1530. Las fuentes registran momentos de gran mortalidad causada por la viruela, el sarampión y otras enfermedades. Las epidemias reportadas mataron cientos e incluso miles de guaraníes que vivían en las encomiendas y en las misiones establecidas por los franciscanos ${ }^{13}$. Sin embargo, el

9 Ibídem, 609.

10 Robert H. Jackson, “The 1781-1782 Smallpox Epidemic in Baja California”, Journal of California and Great Basin Anthropology 3 (verano 1981): 138-143.

11 Reff, “The Jesuit Mission”, 16-31.

12 Ibídem, 23.

13 Ibídem, 22. 
registro demográfico es incompleto y estas epidemias tempranas ocurrieron en una época para la cual los archivos eclesiásticos, particularmente los de bautismos y matrimonios, no se encuentran disponibles. Muchos interrogantes permanecen sin resolver sobre la historia demográfica temprana del Río de la Plata. El primero es la extensión que tuvieron estas epidemias dentro de las poblaciones nativas. Los estudios realizados en otras partes de la América española muestran que los brotes ocurrieron generalmente en grandes centros habitados por poblaciones suficientemente grandes como para propagar el contagio. No existe evidencia para documentar exactamente cómo se extendieron las epidemias a través de una región, aunque la cronología de un brote puede ser documentada comparando los registros de entierros de diferentes comunidades, en aquellas partes donde existen. Las epidemias también se extendieron con las personas que viajaban de comunidad en comunidad portando la infección en sus cuerpos y exponiendo a la enfermedad a la gente susceptible ${ }^{14}$. Estos contactos ocurrieron con mayor frecuencia a través de las diferentes formas en que la gente realizaba su comercio, acudía al trabajo en otras comunidades o por el movimiento de grupos de soldados ${ }^{15}$. La segunda cuestión tiene que ver con la proporción de reincidencia que siguió a los brotes epidémicos, y si los nacimientos lograron compensar las pérdidas y al cabo de cuánto tiempo lo hicieron.

\section{De 1609 a 1641}

En 1609, los jesuitas establecieron en San Ignacio Guazú, en el sureste de Paraguay, la primera misión de la región del Río de la Plata. Los franciscanos también establecieron comunidades misioneras allí, como la de Yaguarón, pero se concentraron en los guaraníes que vivían en las encomiendas. En las décadas siguientes, los jesuitas llegaron a establecer docenas de misiones hacia el este, en la región comprendida entre los ríos Paraná y Uruguay y en las regiones de Iguazú, Tape y Guaira, en lo que hoy en día es Brasil. Se concentraron en los guaraníes que estaban fuera del radio de acción

14 Jackson, en “The 1781-1782 Smallpox Epidemic”, documenta un brote inicial de viruelas en la ciudad de México en 1779, que luego viajó a través del país durante un período de dos años y alcanzó las misiones del norte en 1781. Varios miembros de un grupo de colonos que fueron de Sinaloa a California introdujeron las viruelas en la península, que luego se extendieron a través de los caminos de norte a sur y de misión en misión durante los dos años siguientes. Los mismos colonos ayudaron a diseminar el contagio al viajar hacia el norte a través de la península de California, portando la infección en sus cuerpos y exponiendo a todas las personas susceptibles que encontraron hasta detenerse en una misión. Otros infectados también extendieron el contagio al entrar en contacto con otras personas o al viajar a otras misiones. Y en "Causes of Indian Depopulation in the Pimeria Alta Missions of Northern Sonora”, Journal of Arizona History 24 (1983), 405-429, documenta idéntico brote de viruelas durante el mismo año en las misiones de Pimeria Alta, en el norte de Sonora, localizadas a lo largo del golfo de California en la baja California.

15 Daniel Reff, Disease, depopulation, and culture change in northwestern New Spain, 1518-1764 (Salt Lake City, 1991), sugiere que las epidemias se extendieron por Sinaloa, Sonora y la región vecina por el avance de la conquista y la colonización española a través de las rutas indígenas de comercio que ligaban estas comunidades con el centro de México. 
de las encomiendas en el Paraguay. En 1626-1627, había seis misiones en el distrito de Paraná, con 8.150 tributarios, ocho en Guaira, con 19.780 tributarios y cinco en Tape ${ }^{16}$.

En la década de 1630, sin embargo, las expediciones en busca de esclavos de los bandeirantes de Sao Paulo obligaron a los jesuitas a abandonar las misiones de Iguazú, Guaira y Tape, reubicando algunas de ellas en la zona entre los ríos Paraná y Uruguay ${ }^{17}$. Miles de guaraníes fueron capturados por los cazadores de esclavos, algunos fueron evacuados por los jesuitas y otros miles murieron por las enfermedades que se desataron entre los fugitivos. Una epidemia se propagó en las misiones localizadas al este del río Uruguay entre los años 1634 y 1638, matando 5.563 personas en las siete misiones. Un total de 1.800 murieron en Asunción de Acarigua; 1.115, en Jesús María; 1.142, en Santa Ana; 950, en San Cristóbal; 900, en Santa Teresa; 340, en Santa María, y 316, en Yapeyú ${ }^{18}$. Los registros de los jesuitas no nos proporcionan cifras precisas acerca de la población durante este período. Existen datos disponibles para las misiones de Tape localizadas al este del río Uruguay. Los religiosos de hábitos negros registraron un total de 12.900 familias en 11 misiones, un total de 11.000 bajo la categoría de "almas” en tres misiones y la cantidad de cristianos en seis misiones que representa el total de gentes convertidas, pero que no incluye a los guaraníes recientemente congregados. La cantidad de almas totalizó 3.000 en San José; 5.000, en Candelaria, y 3.000, en Asunción de Aracagua. La cantidad de cristianos fue de 1.600 en San Joaquín; 1.200, en Santa Teresa; 1.600, en San Cosme y Damián; 6.000, en San Tomé; 5.700, en San Pedro y San Pablo, y 4.900, en San Javier ${ }^{19}$.

La población en las misiones jesuitas tuvo momentos de flujo y reflujo durante la década de 1630, debido al éxodo desde los territorios de Guaira, Iguazú y Tape y por la presión ejercida por los bandeirantes en su búsqueda de esclavos en las grandes poblaciones congregadas en las misiones. Los jesuitas recibieron un mínimo apoyo de las autoridades coloniales locales y se vieron obligados a tomar el asunto en sus manos, organizando una milicia de refugiados para combatir a los traficantes de esclavos. En 1641, la milicia de las misiones logró una notable victoria contra los bandeirantes en la batalla de Mbororé, en el río Uruguay. La amenaza representada por los paulistas cesó y las misiones que ahora se concentraban en el distrito comprendido entre los ríos Uruguay y Paraná y el occidente del Paraná lograron su estabilidad.

16 David Owens, “A Historical Geography of the Indian Missions in the Jesuit Province of Paraguay, 1609-1768” (tesis doctoral, Kansas: University of Kansas, 1977), 236.

17 Maeder, "La poblacion de las misiones", 50-56.

18 Owens, "Historical Geography”, 239.

19 Ibídem, 239. 


\section{De 1641 a 1730}

En los noventa años que siguieron a la derrota de los paulistas en Mbororé, la población de las misiones experimentó un crecimiento que solo se frenó durante las epidemias, con lo que los jesuitas aumentaron la cantidad de misiones. Después de 1680 avanzaron de nuevo hacia el este del río Uruguay dentro de la región de Tape, en el actual estado brasileño de río Grande do Sul, el que se habían visto forzados a abandonar por causa de los bandeirantes en la década de 1630. En 1641-1643, la población de las misiones jesuitas totalizó 36.190 habitantes en 20 comunidades. Hacia finales del siglo, en 1682, las cifras llegaron a 61.083 y crecieron hasta 86.173 en 1700 . Gran parte de este crecimiento fue resultado de la reproducción natural y hubo además algunas congregaciones de indios no cristianos, pero sus cifras fueron más bien bajas ${ }^{20}$.

A finales del siglo XVII y comienzos del siglo XVIII los jesuitas ampliaron el número de misiones creando nuevas comunidades con miembros de las ya existentes y reubicando otras en sitios nuevos. En el sureste de Paraguay, reubicaron a Santiago a partir de Guaira en 1659 y crearon las nuevas misiones de Jesús de Tavarange (1685), Santa Rosa (1698) y Trinidad (1706). También regresaron a la región ubicada al este del río Uruguay. El movimiento inicial reubicó las misiones de San Nicolás y San Miguel. Los religiosos establecieron cinco nuevas comunidades con guaraníes provenientes de las misiones ya existentes: San Francisco de Borja (1697), San Luis Gonzaga (1687), San Lorenzo Mártir (1690), establecida con guaraníes de Santa María La Mayor, San Juan Bautista (1698) con parte de la gente de San Miguel, y Santo Ángel Custodio (1707) ${ }^{21}$.

La creación de nuevas comunidades misioneras respondía a dos problemas. El primero era el crecimiento de la población en algunas misiones, que atentaba contra la capacidad de la agricultura para proveer suficiente comida para todos los neófitos. En 1682, por ejemplo, la población de Santa María La Mayor alcanzó un total de 5.171 habitantes, y estaba localizada en un área donde existían varias misiones en tal proximidad que podían llegar a presionar a largo plazo el suministro de alimentos. La segunda razón para la creación de nuevas misiones fue geopolítica. En 1680, los portugueses establecieron Colonia do Sacramento en la Banda Oriental, cerca de la actual Montevideo. Al establecer nuevas misiones al este del río Uruguay, los jesuitas dieron fundamento a los reclamos españoles de soberanía sobre las tierras de la Banda Oriental y aislaron a Colonia do Sacramento de los territorios portugueses del norte.

Entre 1682 y 1732, la población aumentó más del doble, de los 61.083 habitantes reportados en el primer año, hasta los 141.242 reportados en el segundo. Este crecimiento presenta un contraste muy marcado con los patrones de las misiones del norte

\footnotetext{
20 Véase el Apéndice.

21 Carbonell de Masy, Estrategias de desarrollo rural, capítulos 4 y 12.
} 
de México, donde el tamaño de la mayor parte de las poblaciones nativas que vivían en misiones disminuyó y solo presentó algún crecimiento por la congregación de indios no cristianos. Este patrón de rápido crecimiento plantea cuestiones interesantes sobre la forma en que la demografía de las misiones guaraníes podría ser encajada dentro de los patrones generales de las Américas. ¿Reflejó este crecimiento una recuperación de la población guaraní después de más de un siglo de disminución como resultado de las enfermedades y otros factores? Los investigadores han mostrado que la población nativa aumentó en el siglo XVIII en el centro de México, la región andina e incluso en zonas de frontera como Nuevo México, después del declive que siguió a la llegada de los españoles. El modelo que prevalece consiste en una disminución de la población desde el contacto hasta el siglo XVII e incluso hasta el XVIII, seguida por un crecimiento durante el período colonial tardío. Pero establecer este mismo modelo para los guaraníes resulta difícil debido a la precariedad de las fuentes para el período temprano posterior al establecimiento de Asunción, y al hecho de que los jesuitas establecieron misiones con guaraníes que no estaban en las encomiendas, que en algunos casos se ubicaban a cientos de millas de los poblados españoles. Las enfermedades debieron afectar a estas comunidades guaraníes, pero hay muy poca evidencia para verificar si las poblaciones sufrieron o no una disminución después de la década de 1530, aunque esta situación resulta bastante plausible.

La fase de crecimiento terminó abruptamente en la década de 1730, con una serie de epidemias que afectaron las poblaciones misioneras. La recuperación comenzó en la década de 1740, pero una crisis política en la década de 1750 hundió a las misiones, particularmente a aquellas al este del río Uruguay, en una crisis mayor. La siguiente sección examina las crisis demográficas en las misiones jesuitas durante las décadas de 1730 y 1750 con sus patrones, hasta la expulsión de la comunidad religiosa en 1768.

\section{Crisis y declive: de 1730 a 1768}

Una serie de epidemias se desataron en la región en la década de 1730 y causaron disminuciones de corta duración en varias de las misiones. Durante estos años hubo epidemias en 1733, 1735-1736 y 1738-1740. Probablemente se diseminaron a través de las rutas de comercio, cuando un gran número de gente se movilizaba llevando la infección en sus cuerpos. Las misiones jesuitas de Paraguay participaban en el comercio regional, y el ir y venir de personas y bienes facilitaron la expansión del contagio $^{22}$. La gran región del Río de la Plata fue también una frontera en disputa; miles de milicianos guaraníes de las misiones participaron en periódicas campañas contra los

22 Las misiones, por ejemplo, comerciaban con yerba mate en Santa Fe y otros pueblos de la región del Río de la Plata, junto con otros productos que incluían pieles y sebo de ganado. Los jesuitas mantenían oficinas en Santa Fe y Buenos Aires, llamadas Oficios de Misiones, que administraban la compra y venta de los bienes. Véanse Carbonell de Masy, Estrategias de desarrollo rural y Teresa Blumers, La contabilidad en las reducciones guaraníes (Asunción, 1992). 
portugueses o fueron movilizados para emprender acciones militares contra los colonos de Paraguay, en la llamada Revuelta de los Comuneros. Los oficiales reales movilizaron la milicia guaraní a mediados de la década de 1730 para una posible acción contra los portugueses en las fronteras en disputa durante un período de guerra no declarada que se prolongó hasta 1737. Además de esto, en las décadas de 1720 y 1730, la región fue también testigo de una guerra civil en Paraguay, conocida como la Revuelta de los Comuneros, en la cual las autoridades coloniales respondieron movilizando las milicias guaraníes. El transporte de bienes dentro de la región, la movilización de miles de milicianos y el movimiento de tropas crearon las condiciones ideales para la expansión de enfermedades altamente contagiosas como las viruelas y el sarampión.

Muchos investigadores asumen que los pueblos nativos de las Américas no tenían defensas naturales contra las enfermedades del Viejo Mundo introducidas en Norte y Suramérica después de 1492, y que los sobrevivientes de los brotes adquirieron algún grado de inmunidad. Sin embargo, como no existen evidencias para apoyar esta suposición, las referencias a los patrones demográficos de la Europa moderna temprana ayudan a contextualizar los efectos de las epidemias dentro de los pueblos nativos ${ }^{23}$. Viruela, sarampión, peste bubónica y otras enfermedades azotaron las poblaciones europeas y mataron miles de adultos y niños. Estas epidemias usualmente se presentaban una vez cada generación, cuando había suficientes huéspedes potenciales para los patógenos que permitieran diseminar y sostener el contagio, para luego desvanecerse. Además, las enfermedades mataron miles de niños pequeños cada año, y las respiratorias, a jóvenes y viejos durante los meses más fríos del año. Sin embargo, las epidemias periódicas y las enfermedades crónicas solamente frenaron el crecimiento y las poblaciones europeas se recobraron después de las crisis periódicas de mortalidad, dando como resultado que durante la mayor parte de la era moderna temprana experimentaron un lento y moderado crecimiento.

La cronología y la trayectoria del brote de sarampión de 1733 sugieren que pudo haber viajado hacia el norte desde Buenos Aires a lo largo de los ríos Paraná y Uruguay, siguiendo las rutas de comercio establecidas y al regreso de miles de milicianos guaraníes al terminar su servicio en Paraguay. En 1733, la mortalidad más severa se presentó en las misiones del actual sureste de Paraguay, incluyendo San Ignacio Guazú; Nuestra Señora de la Fe, que experimentó el más alto número de muertes de las 30 misiones, con un total de 2.618 en un solo año; Santa Rosa, e Itapúa. Varias de las misiones ubicadas al este del río Paraná también experimentaron una fuerte mortalidad, incluyendo Loreto y Santa Ana, sin ser tan alta en las misiones ubicadas al este del río Uruguay, con las excepciones de La Cruz y San Luis Gonzaga.

23 Para el caso de Europa, véase Flinn, The European Demographic System. 
Una segunda epidemia azotó la región en 1735 y 1736, aunque la mortalidad total no fue tan elevada como en 1733. El brote fue muy localizado. Los mayores índices se presentaron en dos grupos de misiones. El primero, centrado en Loreto, experimentó el mayor número de muertes al año en todos los lugares, con un total de 1.321. Otras misiones afectadas fueron: San Cosme, Santa Ana, San Ignacio Mini, Corpus Christi y San José. Hubo pocos fallecimientos en las misiones vecinas. El segundo grupo se localizó a ambos lados del río Uruguay, en lugares muy cercanos unos de otros. Este grupo incluyó Santa María La Mayor, San Francisco Javier, San Nicolás, con un total de 726 muertes, y San Luis; igualmente, en menor proporción, en los lugares vecinos, incluyendo Mártires y San Lorenzo Mártir.

La tercera de la década, identificada como de viruelas, se desató entre 1738 y 1740. La mortalidad más severa se presentó en 1738, pero la continuidad de un gran número de muertes sugiere que el contagio se extendió primero a través de la parte oriental de la región misionera, a finales de 1739, y en los primeros meses del verano de 1740 en la región del Río de la Plata, que es la época más propicia para que ocurran epidemias. El contagio se desató en las tres comunidades misioneras localizadas en la rivera occidental del río Uruguay, en lo que hoy en día es Corrientes, pero no cruzó el río hacia San Francisco de Borja, ubicada en la rivera opuesta a San Tomé, lo cual sugiere que se tomaron medidas de cuarentena. Dentro de estas tres misiones, la de mayor cantidad de muertes fue La Cruz, donde murieron 1.605 personas en 1739 y otras 186, en $1740^{24}$. La cantidad de fallecimientos en las misiones vecinas de Yapeyú y Santo Tomé fue baja, con variaciones de un lugar a otro. La epidemia mató 1.279 personas en Santa María La Mayor y muchas menos en Mártires y Concepción, localizadas cerca o sobre el río Uruguay. Estas misiones también debieron sufrir grandes pérdidas en los años anteriores.

El contagio mató un gran número de gente en las comunidades misioneras localizadas al este del río Uruguay, y aun aquí la extensión de la epidemia se limitó a cuatro de las siete comunidades. Un total de 1.708 personas murieron en San Nicolás, la más oriental de las misiones; 2.445, en San Luis, y 2.681, en San Lorenzo, localizada al este de San Luis. El contagio aparentemente llegó a San Juan Bautista a finales de 1739 y cobró la vida de 376 personas de la misión. Sin embargo, la mayoría de las víctimas de la epidemia en San Juan Bautista murieron durante los primeros meses de 1740 y hubo 2.400 muertos en todo el año. Curiosamente, la epidemia no acabó con mucha gente en las dos misiones ubicadas más al oriente. En Santo Ángel Custodio murieron 258 en 1739 y la mortalidad en San Miguel estuvo dentro de los rangos normales durante los dos años.

¿De qué forma afectaron las epidemias a la población y a la organización social de las misiones, más allá de la simple reducción de tamaño? Un censo detallado elaborado

24 Véanse en el Apéndice las tablas 11-13. 
en 1735 de la misión Trinidad proporciona algunas pistas ${ }^{25}$. En 1731, la población de Trinidad totalizó 3.569 habitantes y 3.598 en 1733, antes de que el mal atacara el lugar. La de 1733 mató cerca de la mitad de los habitantes de la misión y en 1735 solo quedaban 1.837. Sin embargo, la población se recuperó después de la serie de la década de 1730 y ascendió a 2.680 en 1756 y a 2.558 en 1767 . El contagio reclamó las vidas de los guaraníes a lo largo de todo el espectro de la sociedad misional, incluyendo las familias de los caciques, y hubo un cierto grado de relevo generacional en el liderazgo. Cinco caciques incluidos en el listado de 1735 eran niños menores de 10 años que reemplazaron a sus padres muertos por la enfermedad. La epidemia también destruyó familias, como se evidencia por el gran número de huérfanos (154) y viudos (101). Además, el censo registró bastantes fugitivos (109), principalmente hombres, y muchas mujeres (43) abandonadas por sus maridos. La mayor parte de prófugos dejaron la misión para evitar el servicio militar, pero también lo hicieron para escapar a la enfermedad.

La epidemia redujo en Trinidad cantidad de familias extensas con tres o más hijos. En 1735, el 58\% (888) de la gente estaba agrupada en familias de dos o tres personas, lo

25 Juan Valdevieso, S. J., “Estado del pueblo de la Santísima Trinidad”, Trinidad, septiembre 9 de 1735, Archivo General de la Nación, Buenos Aires, Padrones de Indios, Sala 9-17-3-6.

Estructura de la población de Trinidad en 1735

\begin{tabular}{|c|c|c|c|c|c|c|}
\hline $\begin{array}{c}\text { Personas } \\
\text { por familia }\end{array}$ & $\begin{array}{c}\text { Cantidad } \\
\text { de familias }\end{array}$ & $\begin{array}{c}\text { Población en } \\
\text { cada tipo de familia }\end{array}$ & Huérfanos & Huérfanas & Viudas & Viudos \\
\hline 2 & 258 & 516 & 94 & 50 & 101 & 6 \\
\hline 3 & 124 & 372 & & & & \\
\hline 4 & 93 & 372 & & & & \\
\hline 5 & 34 & 170 & & & & \\
\hline 6 & 13 & 78 & & & & \\
\hline
\end{tabular}

En Ventura Suárez, "Padrón del Pueblo de S. Cosme y Damián que se hizo este presente año 1735”, San Cosme y Damián, agosto 16 de 1735, Archivo General de la Nación, Buenos Aires, Padrones de Indios, Sala 9-17-3-6.

No todas las misiones experimentaron el mismo nivel de pérdida de la población o destrucción de las familias como resultado de las epidemias. Un censo de 1735 de San Cosme, localizada muy cerca de Trinidad, manifiesta una estructura poblacional algo diferente, aunque seguía teniendo un gran número de huérfanos y viudos. A pesar de todo, hubo un gran porcentaje de familias con más de un hijo que sobrevivieron, síntoma de una población que se reproduce a sí misma.

Estructura de la población de San Cosme y Damián en 1735

\begin{tabular}{|c|c|c|c|c|c|c|}
\hline $\begin{array}{c}\text { Personas } \\
\text { por familia }\end{array}$ & $\begin{array}{c}\text { Cantidad } \\
\text { de familias }\end{array}$ & $\begin{array}{c}\text { Población en } \\
\text { cada tipo de familia }\end{array}$ & Huérfanos & Huérfanas & Viudas & Viudos \\
\hline 2 & 141 & 282 & 126 & 167 & 133 & 8 \\
\hline 3 & 121 & 363 & & & & \\
\hline 4 & 95 & 380 & & & & \\
\hline 5 & 64 & 320 & & & & \\
\hline 6 & 45 & 270 & & & & \\
\hline 7 & 19 & 133 & & & & \\
\hline 8 & 3 & 24 & & & & \\
\hline
\end{tabular}

En Ventura Suárez, "Padrón del Pueblo de S. Cosme”. 
que significa que se trataba de una pareja de esposos o de una pareja con un solo hijo. Estas pequeñas familias constituían el 73\% de las de la misión. En contraste, solo había 50 familias (el 6\%) con tres o más hijos, que equivalían al 18\% de la población agrupada en familia. Un censo de 1759 en Santa Ana ayuda a ubicar los datos de Trinidad en su contexto $^{26}$. En 1731, esa misión tenía una población de 4.527 habitantes, pero bajó a 3.716 en 1733. La cifra aumentó y se mantuvo en 5.040 en 1756 y en 5.141 en 1759 . El 31\% de las familias de Santa Ana tenía tres hijos o más, y muchas llegaban hasta siete. El 47\% de la gente estaba agrupada en familias. La población se recuperó de las epidemias de la década de 1730 y creció robustamente, como se evidencia en el gran número de familias con tres o más hijos. El perfil de los habitantes en 1759 era similar al de la estructura de la población misionera antes de las epidemias.

Las enfermedades de la década de 1730 reclamaron las vidas de miles de guaraníes, por lo que la población de las misiones disminuyó en las 30 misiones de 141.242 en 1732 a 73.910 en 1740, después del final de las epidemias. Sin embargo, las misiones del Río de la Plata se recuperaron. El repoblamiento guaraní señala la mayor diferencia frente a las poblaciones indígenas que vivían en la frontera norte de México. Aquel fue un pueblo con altas tasas de fertilidad y de mortalidad, similares a las poblaciones europeas contemporáneas. Las tasas de nacimiento y mortalidad fueron altas y la población creció de una forma baja o moderada. Las epidemias frenaron o detuvieron el crecimiento, pero la población se recuperó.

Las tasas brutas de nacimientos por cada mil habitantes fueron generalmente elevadas, excepto en los años con epidemias ${ }^{27}$, y cuando no hubo restricciones económicas o sociales la población creció considerablemente. Las crisis periódicas de mortalidad afectaron la población y frenaron el crecimiento, pero las cifras generalmente se recuperaron. Al examinar los datos globales de las 30 misiones, se aprecian cuatro grandes crisis de mortalidad (cuando se multiplicó por tres la mortalidad normal) en los años para los cuales existe información: en 1733, 1738, 1739 y 1764. Los mayores brotes epidémicos no solo aumentaron las tasas de mortalidad, sino que tendieron a

26 “Padrón del pueblo de Sta. Ana 1759”, Archivo General de la Nación, Buenos Aires, Padrones de Indios, Sala 9-17-3-6.

Estructura de la población de Santa Ana en 1759

\begin{tabular}{|c|c|c|c|c|c|c|}
\hline $\begin{array}{c}\text { Personas } \\
\text { por familia }\end{array}$ & $\begin{array}{c}\text { Cantidad } \\
\text { de familias }\end{array}$ & $\begin{array}{c}\text { Población en } \\
\text { cada tipo de familia }\end{array}$ & Huérfanos & Huérfanas & Viudas & Viudos \\
\hline 2 & 350 & 700 & 128 & 121 & 131 & 8 \\
\hline 3 & 264 & 792 & & & & \\
\hline 4 & 245 & 980 & & & & \\
\hline 5 & 180 & 900 & & & & \\
\hline 6 & 127 & 762 & & & & \\
\hline 7 & 53 & 371 & & & & \\
\hline 8 & 21 & 168 & & & & \\
\hline 9 & 3 & 27 & & & & \\
\hline
\end{tabular}

27 Véase el Apéndice. 
disminuir las de nacimientos o de nacimientos vivos. En promedio, los guaraníes que habitaban en las misiones vivían entre 20 y 30 años, pero la expectativa de vida promedio al nacer bajó como resultado de las epidemias más fuertes ${ }^{28}$.

Un examen de las tasas brutas de nacimiento y mortalidad en cada misión demuestra la fuerza y también la variación en los niveles de mortalidad durante las epidemias de la década de 1730, con la dispersión geográfica del contagio y los patrones de fertilidad y mortalidad en los años sin epidemias. Aquí examino los datos de 1733, 1736, 1739, 1740, 1741 y 1745 . En 1733, hubo tasas elevadas de mortalidad que superaron el 100 por mil de la población en nueve de las 30 misiones, siendo la más alta de 174 por mil en La Cruz, sobre el río Uruguay, que fue tres veces superior a la normal. Las tasas de mortalidad fueron elevadas y más altas que las tasas de nacimiento en otras 11 misiones. Las tasas brutas de mortalidad en estas comunidades se ubicaron entre 50 y 99 por mil habitantes. La mortalidad fue alta en casi toda la región de las misiones y las epidemias se concentraron en ambos lados del río Uruguay. La de 1735-1736 parece que no fue tan severa como el brote de 1733, y en 1736 el contagio solo afectó un puñado de misiones. La tasa más alta de mortalidad (239,9 por mil) se dio en Loreto y fue de 169,8 por mil en la vecina San Ignacio. La mortalidad también fue elevada en San Cosme, cruzando el río Paraná desde Loreto y San Ignacio, y en Corpus Christi, cercana a San Ignacio. Las tasas de mortalidad fueron elevadas en San Carlos y San José, Santa María La Mayor, San Francisco Javier y San Nicolás, en el río Uruguay.

28 Calculado por Robert McCaa usando Populate e incluido como conjunto de datos en este programa de computador, que usa la proyección inversa para calcular sofisticadas estadísticas demográficas, incluyendo la expectativa promedio de vida al nacer. Populate analiza ejemplos de datos de cinco años y reporta las estadísticas en el punto medio del quinquenio. McCaa utiliza los datos de la investigación de Ernesto Maeder y usa Populate para llenar los vacíos en los datos perdidos.

Esperanza de vida al nacer (EVN) por quinquenios en las misiones guaraníes,

1692-1767

\begin{tabular}{|c|c|c|r|r|r|}
\hline Año & EVN & \multicolumn{1}{|c|}{ Año } & \multicolumn{1}{|c|}{ EVN } & Año & EVN \\
\hline 1692 & 29,7 & 1722 & 26,7 & 1752 & 30,0 \\
\hline 1697 & 28,6 & 1727 & 34,8 & 1757 & 23,2 \\
\hline 1702 & 26,6 & 1732 & 8,8 & 1762 & 6,1 \\
\hline 1707 & 26,7 & 1737 & 0,2 & 1767 & 8,3 \\
\hline 1712 & 32,3 & 1742 & 20,1 & & \\
\hline 1717 & 19,3 & 1747 & 23,0 & & \\
\hline
\end{tabular}

Las cifras de McCaa señalan un promedio en la esperanza de vida media al nacer de 26,8 años en los quinquenios donde hubo más epidemias y de 5,9 en los años de menos epidemias. Calculamos las mismas estadísticas usando como ejemplo los únicos años en que los datos están completos: 17361755 y 1762-1766. Las cifras pueden ser un poco diferentes de las de McCaa, pero se encuentran dentro del mismo rango: $1736-1740=4,5 ; 1741-1745=24,8 ; 1746-1750=24,4 ; 1751-1755=29,9$; 1762-1766 = 9,4 años. El promedio en los años sin epidemias fue de 26,4 años al nacer y de 7 años al nacer durante los períodos críticos de mortalidad. 
La epidemia de 1738-1740 generó una severa crisis de mortalidad. El registro de nacimientos y entierros no está disponible para 1738, pero existen datos para los dos años siguientes. La más fuerte mortalidad de 1739 se centró en las misiones localizadas entre los ríos Paraná y Uruguay, junto con varias misiones al oriente del río Uruguay. Esta distribución espacial de los entierros sugiere que la mortandad en 1738 pudo haber sido más severa en las misiones ubicadas al occidente y al noreste del Río Paraná, los distritos surorientales del actual Paraguay. El contagio se diseminó probablemente hacia las misiones de este país. Las tasas brutas de mortalidad se situaron entre 100 y 200 por mil habitantes en tres misiones, incluida Trinidad, ubicados cerca de la orilla occidental del Paraná. En San Tomé fue de 230,8 por mil, en la rivera occidental del río Uruguay, y fue entre cuatro y cinco veces más alta del promedio. Las muertes fueron muy frecuentes en cinco misiones y alcanzaron nueve o diez veces lo normal. La tasa bruta de mortalidad alcanzó 336,8 por mil, es decir, casi el 34\% de la población en San Nicolás; 416,6 por mil, en La Cruz, y 565,4; 565,1 y 556,9 por mil, en Santa María La Mayor, San Luis Gonzaga y San Lorenzo Mártir, respectivamente. En otras palabras, más del 50\% de la población de las tres comunidades murió en el transcurso del año. La mayoría, en las comunidades misioneras ubicadas al este y a lo largo del río Uruguay.

La mortalidad regresó a niveles normales y a estándares en los cuales los nacimientos eran mayores que las muertes y la población de las misiones empezó a crecer de nuevo. La excepción fue La Cruz, donde los decesos estuvieron a punto de ser tan frecuentes como en 1739. Las viruelas probablemente alcanzaron la misión de San Juan Bautista a finales de 1739 y devastaron la población durante los primeros meses de 1740. La mortalidad alcanzó el 485 por mil, es decir, 48\% de los habitantes, y la población bajó de 4.949 a 2.171 en 1739. En las otras misiones las viruelas comenzaron a desaparecer a medida que disminuían los huéspedes potenciales o que los neófitos guaraníes morían o se recuperaban. Durante los años siguientes las poblaciones de las misiones se recuperaron lentamente de las pérdidas sufridas en la década de 1730. Los nacimientos de nuevo superaron a las muertes y la población nuevamente empezó a crecer.

La segunda crisis del período fue resultado de la firma del Tratado de Madrid en 1750 que intentó establecer los límites coloniales entre España y Portugal en Suramérica. Una provisión del tratado estipulaba la transferencia del puesto avanzado portugués de Colonia do Sacramento, establecido en 1680 en el actual Uruguay, a cambio de unos 500.000 kilómetros cuadrados de territorio en lo que hoy es Río Grande do Sul, al norte de Uruguay. El área cedida incluía las siete misiones ubicadas al oriente del río Uruguay, junto con sus extensas estancias, y Yapeyú, La Cruz y Santo Tomé. Los habitantes, que ascendían a 29.191, fueron reubicados en territorio español. A los neófitos guaraníes se les permitió llevar sus bienes muebles. Si no se trasladaban en un año se convertirían en vasallos de Portugal. Una cláusula secreta del tratado esti- 
Figura 2

Diagrama de la misión San Miguel, c. 1756



Cortesía del IPHAN. Este diagrama muestra las casas de los neófitos donde miles de guaraníes vivieron muy próximos. Este patrón de asentamiento compacto ayuda a explicar la rápida expansión y las altas tasas de mortalidad durante las epidemias. 
Figura 3

\section{Diagrama de la misión San Juan Bautista, c. 1756}

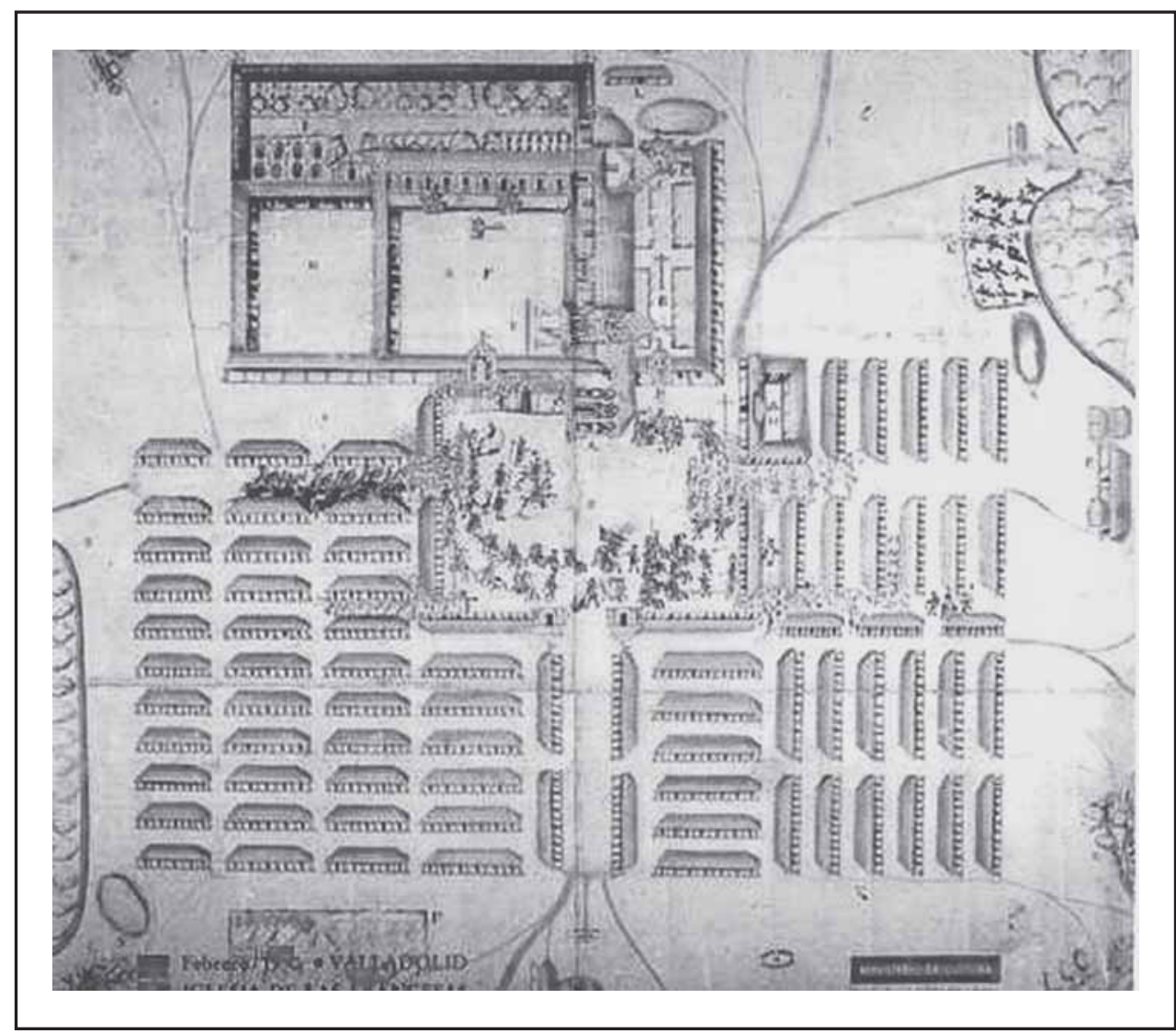

Fuente: cortesía del IPHAN. 
pulaba que las fuerzas españolas y portuguesas colaborarían en la expulsión de los guaraníes si se resistían. Los oficiales españoles esperaban que los misioneros jesuitas los convencieran de reubicarse y la corona ofreció a los jefes 28.000 pesos como compensación ${ }^{29}$.

Los guaraníes se resistieron a la reubicación forzosa y enfrentaron dos invasiones de las tropas españolas y portuguesas. En 1754, compelieron a los españoles a retirarse de sus tierras, pero experimentaron una gran derrota en febrero de 1756, que permitió a una expedición lusohispánica ocupar las misiones. El ejército de ambas naciones derrotó a la milicia guaraní en la batalla de Caibate, el 10 de febrero de 1756. Los europeos tuvieron tres muertos y 10 heridos, frente a 1.511 bajas guaraníes y 154 capturados. Después de la batalla, el ejército lusohispánico ocupó las siete misiones. Los guaraníes en retirada abandonaron San Miguel y San Luis Gonzaga, dejando los edificios principales en llamas. Los españoles ocuparon Santo Ángel y la usaron como base de operaciones, y los portugueses, San Juan Bautista $^{30}$. España y Portugal anularon posteriormente el tratado de 1750 y los españoles retomaron el control de las siete misiones. Las aldeas misioneras sufrieron muchos daños físicos además que el ejército invasor lusohispano había consumido el ganado de las estancias para su alimentación ${ }^{31}$. España y Portugal entraron en guerra en las fronteras del Río de la Plata en la década de 1760 después de que aquella denunció el Tratado de Madrid, y solo resolvieron el conflicto limítrofe con la firma del Tratado de San Ildefonso, en 1777. La rebelión y la presencia de tropas españolas y portuguesas en el territorio misionero afectaron el funcionamiento de la economía de las misiones. Además, inmediatamente después de la ocupación de las misiones, la población guaraní se dispersó. Un censo de 1756 solamente contó 14.284 habitantes en las siete misiones, de los casi 29.000 que había al comienzo de la guerra ${ }^{32}$.

La insurrección guaraní de la década de 1750 causó una ola de emigración desde las siete misiones ubicadas al otro lado del río Uruguay. Después del fracaso de la rebelión, los españoles reubicaron cerca de 12.000 neófitos en las misiones ubicadas al occidente del río Uruguay. Durante los primeros años de la década de 1760 solamente vivían unos 15.000 guaraníes después del regreso de los españoles como consecuen-

\footnotetext{
${ }^{29}$ Édgar y Alfredo Poenitz, "Herencia misionera”, página web (Posadas, Argentina: TerritorioDigital.com, 2004), obtenido de la red mundial el 24 de agosto de 2004, 12:00 horas. http:// www.herenciamisionera.com.ar/, cap. 11.

$30 \quad$ Ibídem, cap. 12.

31 Ibídem.

32 Maeder, “Fuentes jesuíticas”, 45-57.
} 
cia de la anulación del Tratado de Madrid ${ }^{33}$. El doble de ellos vivía en los siete establecimientos en 1750. Los portugueses también reubicaron neófitos en Río Grande do Sul y los organizaron en varias comunidades llamadas aldeias, donde trabajaron en las estancias cercanas. Una de estas comunidades, Aldeia de Anjos, contaba con 3.500 habitantes en 1762, pero las cifras bajaron a 2.563 en 1779, a 1.362 en 1784 y a 300 en $1814^{34}$.

Los neófitos guaraníes también migraron voluntariamente hacia la frontera en disputa de la Banda Oriental (Uruguay) y establecieron nuevas comunidades independientes de los jesuitas. Una de ellos fue llamada Las Víboras y fue establecida en 1758 después del fin del levantamiento guaraní: cerca de 1.500 personas vivían allí en 1800 . Un análisis de las 1.045 entradas en los registros de bautismos de Las Víboras para los años de 1770 a 1811 brinda evidencia de los diversos orígenes de los residentes. La mayoría, es decir 784 (75\% del total), eran hijos de los neófitos que alguna vez vivie-

33 Flores, Reduçoes, 118-120. En 1764 más de 5.000 refugiados de las misiones ubicadas al extremo este todavía vivían en los lugares donde habían sido reubicados por las autoridades españolas.

Lugar de residencia de los neófitos guaraníes de las siete misiones del otro lado del río Uruguay en 1764.

\begin{tabular}{|c|c|c|c|}
\hline Misión & Neófitos & Otras misiones & $\begin{array}{c}\text { Cantidad } \\
\text { de neófitos }\end{array}$ \\
\hline \multirow[t]{5}{*}{ Santo Ángel } & \multirow[t]{5}{*}{1.310} & San Francisco Javier & 911 \\
\hline & & Mártires & 381 \\
\hline & & Concepción & 354 \\
\hline & & Loreto & 127 \\
\hline & & San Ignacio Mini & 29 \\
\hline \multirow[t]{5}{*}{ San Juan Bautista } & \multirow[t]{5}{*}{1.508} & Mártires & 8 \\
\hline & & Corpus Christi & 317 \\
\hline & & Itapúa & 886 \\
\hline & & Loreto & 316 \\
\hline & & San Ignacio Mini & 770 \\
\hline San Miguel & 2.679 & N.S. de la Fe & 47 \\
\hline \multirow[t]{2}{*}{ San Lorenzo } & \multirow[t]{2}{*}{1.149} & San Ignacio Mini & 11 \\
\hline & & N.S. de la Fe & 13 \\
\hline \multirow[t]{4}{*}{ San Luis Gonzaga } & \multirow[t]{4}{*}{2.381} & San Ignacio Mini & 10 \\
\hline & & Jesús & 545 \\
\hline & & Trinidad & 607 \\
\hline & & San Carlos & 32 \\
\hline \multirow[t]{3}{*}{ San Francisco de Borja } & \multirow[t]{3}{*}{2.738} & San Ignacio Mini & 10 \\
\hline & & Jesús & 82 \\
\hline & & Trinidad & 63 \\
\hline San Nicolás & 3.925 & & \\
\hline
\end{tabular}

Fuente: “Catálogo de la numeración de las doctrinas del río Paraná” y “Catálogo de la numeración de las doctrinas del río Uruguay”, Manuel Gondra Collection, MG 592, Benson Latin American Collection, General Libraries of the University of Texas at Austin.

34 Ibídem, 121-126. 
ron en las misiones jesuitas. Otros provenían de las misiones franciscanas al sur de Paraguay y de otras áreas de la gran región del Río de la Plata. Los habitantes de Las Víboras abandonaron la comunidad en 1846 debido a un ataque durante una guerra civil en Uruguay ${ }^{35}$

35 Luis Rodolfo González Rissotto, "La importancia de las misiones jesuíticas en la formación de la sociedad uruguaya”, Estudios Ibero-Americanos 15, núm. 1 (junio 1989): 191-214. Las autoridades españolas intentaron regresar a los fugitivos a las antiguas misiones. Por ejemplo, en 1790, contaron el número de guaraníes en sus jurisdicciones con el fin de realizar un esfuerzo para retornarlos a sus comunidades. Tomás Estruday, de Colonia do Sacramento, en la Banda Oriental, contó 13 fugitivos, incluyendo siete de las antiguas misiones jesuitas. Véase: Tomás Estruday, "Relación de los indios que se han recogido de la provincia del Paraguay y de los pueblos de misiones del Uruguay y Paraná", Colonia do Sacramento, marzo 31 de 1790, Archivo General de la Nación, Buenos Aires, Padrones de Indios, sala 9-17-3-6. Un segundo reporte mencionó más de 300 fugitivos en las jurisdicciones de la Villa de Concepción del Uruguay, San José y San Antonio. A pesar de los esfuerzos, la emigración continuó.

Cantidad de guaraníes encontrados en las jurisdicciones de la Villa de Concepción del Uruguay, San José de Gualeguayes y San Antonio de Gualeguay en 1790

\begin{tabular}{|c|c|c|c|}
\hline \multicolumn{4}{|c|}{ En Villa de Concepción: } \\
\hline Antigua mission & Guaranies & Antigua misión & Guaranies \\
\hline Yapeyú & 21 & Concepción & 21 \\
\hline San Carlos & 15 & San Luis & 5 \\
\hline Loreto & 14 & San Nicolás & 5 \\
\hline La Cruz & 8 & Sta. María La Mayor & 4 \\
\hline San Tomé & 4 & San Javier & 3 \\
\hline San Borja & 5 & Mártires & 2 \\
\hline Sto. Angel & 1 & Apóstoles & 6 \\
\hline San Juan & 3 & San José & 8 \\
\hline San Miguel & 2 & Sta. Ana & 5 \\
\hline Candelaria & 2 & San Ignacio & 6 \\
\hline Corpus Christi & 3 & Trinidad & 2 \\
\hline Jesús & 5 & Itapúa & 9 \\
\hline San Cosme & 4 & Santiago & 4 \\
\hline Sta. Rosa & 5 & La Fe & 1 \\
\hline Guasú & 1 & & \\
\hline \multicolumn{4}{|l|}{ En San José: } \\
\hline Antigua mission & Guaranies & Antigua mision & Guaranies \\
\hline Loreto & 1 & Mártires & 1 \\
\hline San Tomé & 1 & Yapeyú & 3 \\
\hline Corpus Christi & 1 & San Juan & 1 \\
\hline Concepción & 1 & Sta. Ana & 1 \\
\hline San Miguel & 1 & Apóstoles & 1 \\
\hline \multicolumn{4}{|l|}{ En San Antonio: } \\
\hline Antigua mision & Guaranies & Antigua misión & Guaranies \\
\hline Yapeyú & 8 & San José & 1 \\
\hline Sta. Ana & 2 & Loreto & 2 \\
\hline San Luis & 1 & Candelaria & 2 \\
\hline Sta. Rosa & 1 & La Cruz & 3 \\
\hline Apóstoles & 2 & Corpus & 3 \\
\hline San Cosme & 1 & San Juan & 1 \\
\hline Sto. Ángel & 1 & & \\
\hline
\end{tabular}

Fuente: Vicente Jiménez, “Lista de los indios guaranís procedentes de los pueblos de misiones que se hallan en las Villas de Concepción del Uruguay, San Joseph de Gualeguayes y San Antonio del Gualeguay y sus partidos”, Villa de Concepción, abril 26 de 1790, Archivo General de la Nación, Buenos Aires, Padrones de Indios, Sala 9-17-3-6. 
Las poblaciones de las otras misiones jesuitas se recuperaron después de la crisis de mortalidad en la década de 1730. En 1762 había 102.988 habitantes. Sin embargo, otra epidemia de viruelas en 1764 redujo se cantidad nuevamente. La campaña militar en curso entre los españoles y los portugueses por el control de Laguna de los Patos y Río Grande do Sul, que involucraba miles de soldados, creó las condiciones necesarias para la expansión del contagio en la región. La población disminuyó hasta 85.266 en 1765, al año siguiente del brote, pero creció tímidamente en los años posteriores. En 1768, cuando Carlos III ordenó la expulsión de los jesuitas, la población de las misiones era de 88.864 habitantes.

\section{De 1768 a 1827}

Después de la expulsión de los jesuitas, el gobierno nombró administradores civiles en las comunidades misioneras. Como sugiere Julia Sarrel, la transición hacia la administración civil causó una ruptura entre el sistema económico jesuita que compartía recursos entre las comunidades y el nuevo sistema que hacía un gran énfasis en la producción de cada misión individual con muy poco o ningún intercambio entre ellas ${ }^{36}$. Un aspecto de la ruptura en el sistema jesuita fue la emigración de las antiguas misiones.

En los años inmediatamente posteriores al éxodo de los jesuitas, la emigración continuó, pero a una escala limitada. En 1767 se reportaron 88.796 guaraníes en las misiones y la cantidad disminuyó a 80.891 cinco años después, en 1772. La mayor disminución ocurrió durante la década de 1770, y en 1783 todavía vivían 56.092 en las misiones. Las cifras se estabilizaron en las décadas de 1780 y 1790 , pero también fluctuaron. En 1791 la población alcanzó la cifra de 44.677 y luego, en 1793, 51.991, aunque este número también incluye a las personas que seguían apareciendo en los registros pero estaban ausentes. En 1801 se reportaron 45.637 habitantes en las misiones.

Otra causa importante del declive fue la destrucción física de muchas de las misiones localizadas en lo que hoy en día es Río Grande do Sul (Brasil) y Misiones (Argentina) durante las guerras entre Portugal, Argentina y Paraguay por el control de las fronteras en la Banda Oriental y las áreas vecinas en las tres primeras décadas del siglo XIX. En 1801, durante una guerra entre España y Portugal, una milicia portuguesa ocupó las siete misiones ubicadas al este del Río Uruguay que habían sido devueltas a España después del fiasco del Tratado de Madrid y la Guerra Guaraní $^{37}$. Los portugueses distribuyeron las tierras de las misiones en concesiones

36 Julia Sarreal, “Paraguay Missions: Illusions of Prosperity and Decay, 1700-1800” (ponencia presentada en la reunión anual de la Conference on Latin American History, Washington, D.C., 9 de enero 2004).

37 Poenitz, “Herencia misionera”, cap. 21. 
Figura 4

Diagrama de la misión Candelaria, 1767

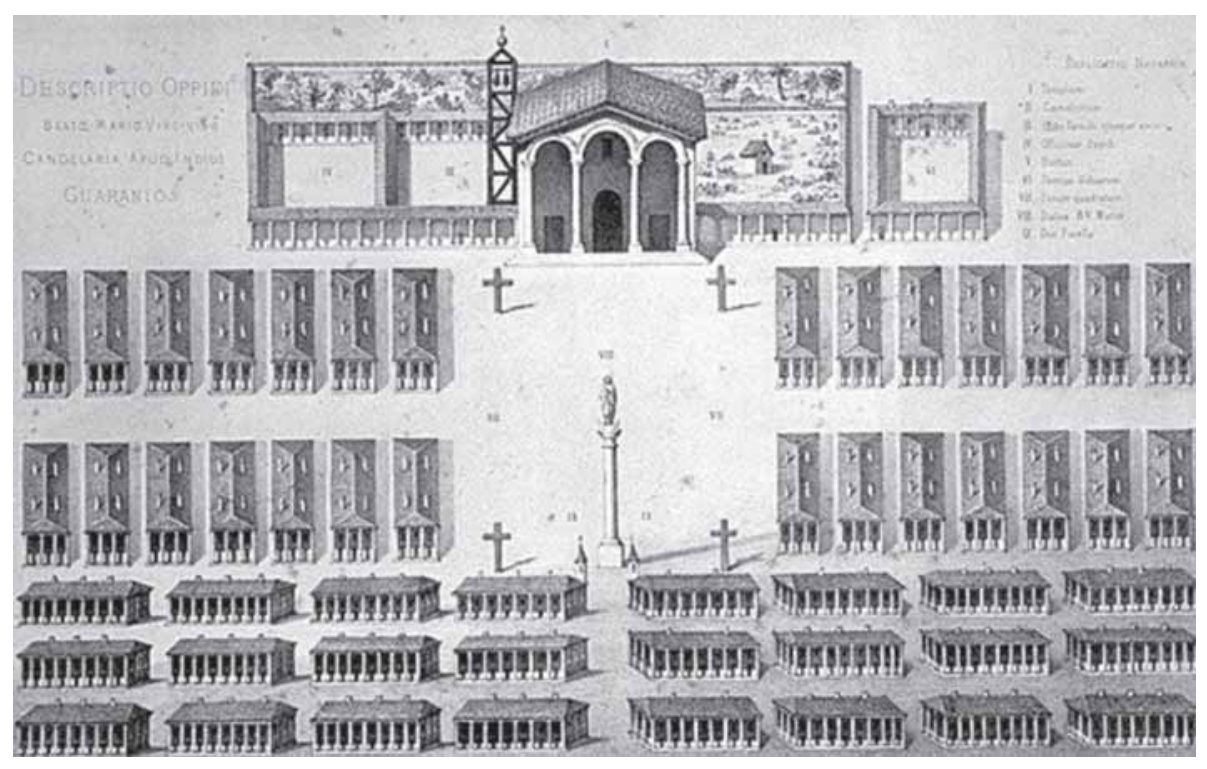

Fuente: cortesía del IPHAN. 


\section{Figura 5}

\section{Ruinas de San Lorenzo Mártir}

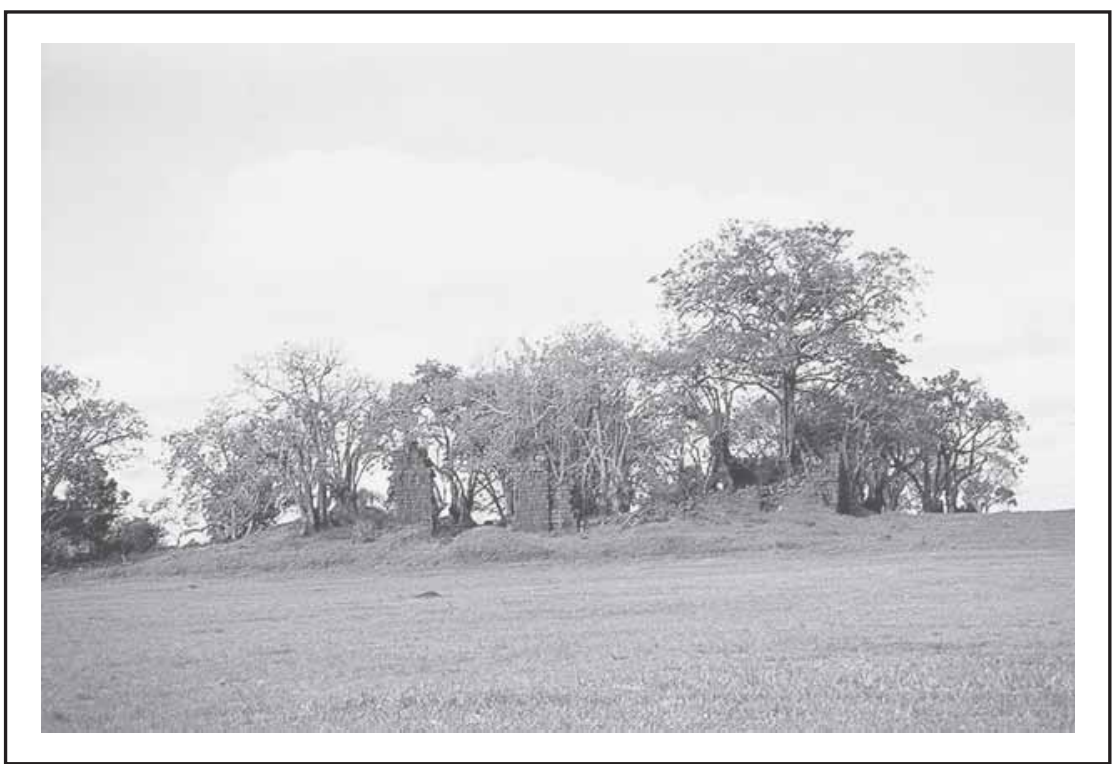

Fotografías cortesía de Henrique Chagas. San Lorenzo Mártir fue una de las siete misiones transferidas al control de Portugal en el Tratado de Madrid de 1750.

\section{Figura 6}

\section{Ruinas de Santa Ana, cerca del río Paraná en la actual Argentina}

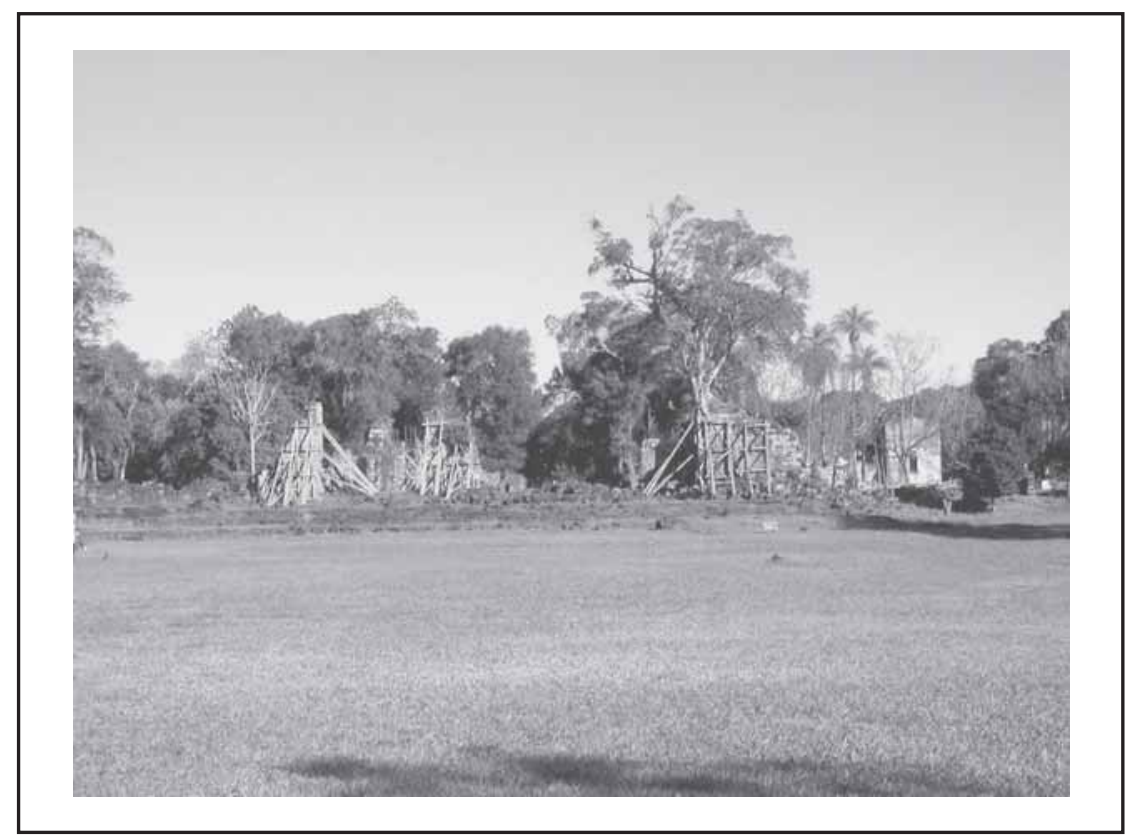


llamadas sesmarias ${ }^{38}$ Las ubicadas más al oriente sirvieron como base de operaciones de las invasiones portuguesas a la zona comprendida entre los ríos Uruguay y Paraná durante las turbulentas décadas de 1810 y 1820 . Hubo invasiones en 1811 y 1812, y luego en 1817 y 1818. Durante esta última murieron 3.190 personas en Misiones, 360 fueron tomadas como prisioneros, y los portugueses saquearon muchas de las misiones. Además, una gran batalla ocurrió en los primeros días de abril de 1818 en San Carlos, resultando severamente dañada la iglesia y las construcciones aledañas. Los paraguayos también intentaron ejercer soberanía en el territorio entre el Paraná y el Uruguay y ocuparon y saquearon misiones a lo largo de la rivera oriental del río Paraná en 1817, como San Ignacio, Santa Ana, Loreto y Corpus Christi, entre otras ${ }^{39}$.

Los guaraníes abandonaron muchas de las misiones ubicadas en la zona de guerra y buscaron refugio en otras partes o fueron forzados a reubicarse. La odisea de un grupo de guaraníes habitantes de las siete misiones al este del Uruguay ilustra cómo se vieron envueltos los refugiados en las inestables condiciones políticas de la región. En 1828, durante las últimas etapas de la guerra entre Argentina y Brasil por el Uruguay, un tal Fructoso Rivera saqueó las siete misiones y llevó a más de 6.000 guaraníes de regreso al Uruguay, donde estableció un nuevo asentamiento junto al río Paraná, llamado Santa Rosa de la Bella Unión. Los refugiados permanecieron en el sitio du-

38 Flores, Reduçoes, 127. Ha sobrevivido un fragmento de los registros de bautismos y entierros de San Francisco de Borja, ubicada en la rivera oriental del río Uruguay, opuesta a San Tomé. En él se aprecia que después de la ocupación portuguesa la vida sacramental normal de la población continuó sin interrupciones y que curas con apellidos españoles siguieron llevando los registros. También se percibe en estos documentos un crecimiento continuo de la población y una recuperación después de la epidemia de 1809.

Bautismos y entierros registrados en San Francisco de Borja, 1798-1811

\begin{tabular}{|l|r|r|r|}
\hline Año & Bautismos & Entierros & $+/$ - Neto \\
\hline 1798 & 125 & & \\
\hline 1799 & 118 & & \\
\hline 1800 & & 88 & \\
\hline 1801 & & 97 & \\
\hline 1802 & & 100 & \\
\hline 1803 & & 91 & \\
\hline 1804 & 163 & 68 & 95 \\
\hline 1805 & 109 & 62 & 47 \\
\hline 1806 & 105 & 64 & 41 \\
\hline 1807 & 161 & 69 & 92 \\
\hline 1808 & 144 & 64 & 80 \\
\hline 1809 & 147 & 262 & -115 \\
\hline 1810 & 132 & 75 & 57 \\
\hline 1811 & 133 & 70 & 63 \\
\hline
\end{tabular}

Fuente: Registros bautismales y de entierros de San Francisco de Borja, Diócesis de Uruguaiana, Brasil.

39 Poenitz, “Herencia misionera”, capítulos 26-28. 
rante cinco años, pero se vieron obligados a abandonarlo después de un ataque de una milicia de la facción de los Colorados, involucrados en una guerra civil contra los Blancos. Un grupo de 860 personas oriundas de las siete misiones establecieron una nueva comunidad llamada San Borja del Yi cuya población alcanzó cerca de 3.500 habitantes. De los 860 que se establecieron en San Borja del Yi, 139 venían de San Francisco de Borja; otros 350, de las seis misiones restantes al este del Uruguay, y 371, de Yapeyú, La Cruz, San Tomé y Corpus Christi ${ }^{40}$. Las misiones localizadas en el actual sureste de Paraguay no experimentaron destrucciones violentas ni se vieron involucradas de guerra. Continuaron existiendo como comunidades nativas autónomas hasta 1848, cuando el dictador paraguayo Carlos Antonio López decretó la secularización de las comunidades y la incautación de los bienes de las misiones $^{41}$.

Un examen de las tasas vitales y de la estructura de género y edades ayuda a explicar el crecimiento de la población misionera y las recuperaciones que siguieron a las epidemias, principalmente después de la crisis de mortalidad de la década de 1730. Primero se examinará la fertilidad, la mortalidad y la esperanza de vida.

\section{Fertilidad, mortalidad, esperanza de vida y estructura de edades y géneros}

¿Cómo se pueden caracterizar a las poblaciones guaraníes que vivían en las misiones? Según he señalado anteriormente, estos grupos tenían altas tasas de fertilidad y mortalidad, similares a los de los europeos contemporáneos. Las mujeres guaraníes daban a luz muchos niños pero también moría mucha gente. Sin embargo, en la mayoría de los años, las tasas de nacimiento fueron más altas que las tasas de mortalidad, cuando no hubo epidemias. La población de las misiones creció a partir de tasas bajas o moderadas. La Tabla 8 resume las tasas brutas de nacimiento y mortalidad en 1741 y 1745 , después de la crisis de la década de 1730. En ambos años, los nacimientos fueron superiores a las muertes y la población comenzaba a recuperarse. Las tasas de nacimiento y mortalidad en años seleccionados de la población de todas las misiones muestran igualmente que la mayor parte del tiempo los nacimientos fueron más altos que las muertes, y que en los años sin epidemias la cantidad de gente creció. Los jesuitas no transformaron ni trastornaron radicalmente la forma de vida de los guaraníes, como sucedió en las misiones del norte de México. Más aún, preservaron su estructura sociopolítica y otorgaron a los caciques una considerable autoridad.

40 González, “La importancia de las misiones”, 201-203.

41 Thomas Whigham, “Paraguay's Pueblos de Indios: Echoes of a Missionary Past”, en The New Latin American Mission History, eds. Erick Langer y Robert H. Jackson (Lincoln, 1995). 
Los patrones de mortalidad también se asemejan a los de los europeos, con una excepción. En los años sin epidemias, murieron más niños pequeños que adultos. Aunque los censos solamente utilizan el término párvulo (por lo general niños menores de 10 años) para identificar los entierros de niños, la mayoría debió morir antes de cumplir su primer año o antes de alcanzar su quinto cumpleaños. Esta situación era similar a los patrones de mortalidad en las poblaciones europeas de la época. En los años con epidemias una gran cantidad de niños y adultos murieron, pero generalmente la mortandad fue mayor en los adultos. En 1733 y 1736, por ejemplo, murieron 400 adultos y 371 niños, y 1.655 adultos y 1.026 niños, respectivamente, en la misión San Lorenzo. La gran cantidad de entierros de adultos durante las epidemias indica muertes de individuos nacidos desde el brote previo del contagio.

¿Cuánto vivían los guaraníes nacidos en las misiones? Los datos del total de la población, analizados usando el programa de microcomputador Populate, han arrojado una esperanza promedio de vida al nacer para 1690-1769 que se puede promediar en 26,8 en años sin epidemias y en 5,9 para los años con epidemias ${ }^{42}$. Esto resulta acorde con lo que sucedía en las poblaciones europeas de la época. Durante la crisis de la década de 1730, la esperanza de vida fue de 8,8 años para el quinquenio de 1730-1734, que incluye la epidemia de 1733. Pero fue mucho más baja al finalizar la década, llegando a 0,2 años al nacer. La década de 1760 fue un segundo período de depresión en la esperanza de vida, que llegó a ser de 6,1 años al nacer durante el quinquenio de 17601764 y de 8,3 en los años siguientes.

Los padrones detallados proporcionan importantes pistas sobre la estructura de la población de las misiones, especialmente indicadores de si crecen o no por reproducción natural. El censo más detallado fue un conteo realizado en Corpus Christi en 1759. Hay muchos censos detallados que dividen a la población en grupos familiares, pero este es el único en el que los jesuitas también anotaron la fecha de bautismo del grueso de la población, lo que permite reconstruir la estructura de edades. Había 4.530 habitantes, más otros 112 identificados como guananas, probablemente un grupo de la región de El Chaco congregado en la misión en 1724, 1730 y 1754. Los guananas de Corpus Christi no han sido incluidos en el análisis porque la fecha de bautismo de los adultos, cuando aparece, no se corresponde con la fecha de nacimiento, como sucede con el grueso de la población. La misión presentaba un desbalance de género, con más mujeres que hombres (2.321 y 2.209). Además, las que alcanzaron una edad de 50 en adelante sobrevivían mucho más que los hombres. Había 206 hombres mayores de 50 años y solamente

42 Véase nota 28 a pie de página. 
seis mayores de 70 . En contraste, había 220 mujeres mayores de 50 años y 20 mayores de $70^{43}$.

Los datos del censo muestran que Corpus Christi fue una comunidad relativamente cerrada, como indican los patrones de elección matrimonial. Con la excepción de un grupo de mujeres originarias de la región de El Chaco y de las misiones vecinas, la gran mayoría de guaraníes se casaron con mujeres de la misma misión. Hombres de Corpus Christi se casaron con ocho mujeres guanana de los grupos congregados en 1724, 1730 y 1754 y con una mujer abipone, otro grupo de El Chaco. También contrajeron matrimonio con ocho mujeres de las misiones vecinas: una de San Francisco de Borja, dos de Loreto, una de Santa Rosa, una de San Carlos, dos de Itapúa y una de San Ignacio. Las mujeres guaraníes se casaron generalmente poco tiempo después de alcanzar la pubertad, en un rango entre 12, 16 y 19 años. Tenían muchos hijos, pero la diferencia entre los niños que nacían y los que alcanzaban dos años indica también una alta tasa de mortalidad. A pesar de todo, suficientes niños, sobre todo niñas, sobrevivieron a la pubertad para formar nuevas familias y contribuyeron al aumento de la población.

La estructura de edades de Corpus Christi muestra los efectos de las epidemias, incluyendo aquellas de la década de 1730, lo que se aprecia en cohortes que son más pequeñas de lo que deberían ser, teniendo en cuenta la estructura de edades de la misión. Las cohortes entre 20 y 24 años y entre 25 y 29 años fueron más pequeñas que las anteriores y posteriores, mostrando pérdidas durante las epidemias de la década de 1730. La cohorte femenina entre 20 y 24 años es más pequeña que la masculina, y ambas muestran pérdidas por la epidemia de viruelas que asoló la región entre

43 "Matrícula deste pueblo de Corpus Christi".

Estructura de edades y géneros de Corpus Christi en 1759

\begin{tabular}{|l|r|r|r|r|}
\hline \multicolumn{1}{|c|}{ Cohorte } & Hombres & Porcentaje & Mujeres & Porcentaje \\
\hline $0-4$ & 339 & 15,4 & 372 & 16,0 \\
\hline $5-9$ & 346 & 15,7 & 324 & 13,9 \\
\hline $10-14$ & 324 & 14,7 & 380 & 16,4 \\
\hline $15-19$ & 261 & 11,8 & 269 & 11,6 \\
\hline $20-24$ & 160 & 7,2 & 133 & 5,7 \\
\hline $25-29$ & 82 & 3,7 & 89 & 3,8 \\
\hline $30-34$ & 146 & 6,6 & 148 & 6,4 \\
\hline $35-39$ & 159 & 7,2 & 177 & 7,6 \\
\hline $40-44$ & 104 & 4,7 & 97 & 4,2 \\
\hline $45-49$ & 70 & 3,2 & 64 & 2,8 \\
\hline $50-54$ & 85 & 3,9 & 89 & 3,8 \\
\hline $55-59$ & 53 & 2,4 & 47 & 2,0 \\
\hline $60-64$ & 49 & 2,2 & 42 & 1,8 \\
\hline $65-69$ & 13 & 0,5 & 22 & 1,0 \\
\hline $70+$ & 6 & 0,3 & 20 & 0,9 \\
\hline Sin datos & 12 & 0,5 & 48 & 2,1 \\
\hline Total & 2.209 & & 2.321 & \\
\hline Guananas & 52 & & 60 & \\
\hline Total & $\mathbf{2 . 2 6 1}$ & & & \\
\hline Población total & $\mathbf{4 . 6 4 2}$ & & & \\
\hline
\end{tabular}


1738 y 1740. Igualmente, el azote de 1733 afectó la población de niños pequeños, lo que se refleja en una pequeña cohorte de 25 a 29 años. La que se desató en 1738 fue la más fuerte de las tres que hubo en la década pero la población de la misión recuperó sus pérdidas a través de la reproducción natural. Otra fuerte epidemia, un brote de viruelas sucedido en 1718, mató gran número de niños de ambos sexos entre 1714 y 1719 .

La estructura de géneros también explica la habilidad de las poblaciones misioneras para crecer. Las guaraníes tuvieron cantidades casi iguales o un poco superiores de niñas y mujeres que de niños y hombres. Los jesuitas dividieron administrativamente las misiones paraguayas en dos grupos: aquellas agrupadas en torno al río Paraná y las que se situaron al oriente y al occidente del río Uruguay. En 1724, los habitantes de ambos grupos evidenciaban un patrón con mayor número de mujeres que de hombres. En las misiones del Paraná hubo 28.863 mujeres y niñas comparadas con los 25.408 hombres y niños, del mismo modo, 33.107 mujeres y 29.588 hombres en el río Uruguay. En lugares escogidos al azar se presentan generalmente desbalances con un número ligeramente mayor de mujeres que de hombres. La disparidad refleja, en parte, la migración de estos. Resulta interesante apreciar que hubo considerablemente más viudas que viudos, con 2.980 y 3.880 en la primera categoría y 109 y 236 en la segunda en los dos grupos de misiones. Esta última categoría de datos subraya la importancia de la cotiguazu, la residencia separada de los viudos, como una institución social de las misiones. Los patrones fueron similares en 1740 y 1741, con más mujeres que hombres y considerablemente más viudas que viudos ${ }^{44}$. Además, los datos muestran que las misiones individuales tendieron a tener más mujeres que hombres.

44 “Catálogo de la numeracion anual de las doctrinas del río Paraná año 1724”; “Catálogo de la numeración anual de las doctrinas del río Uruguay, 1724”; “Catálogo de la numeración anual de las doctrinas del río Paraná año 1740”; “Numeración anual de los pueblos del río Uruguay año de 1740”; “Catálogo de la numeración anual de las doctrinas del río Paraná año 1741”; "Numeración anual de los pueblos del río Uruguay año de 1741”. Los originales se encuentran en el Archivo Nacional, Asunción, Paraguay. Quisiera agradecer a Barbara Ganson por darme las copias de estos documentos. Los censos detallados de misiones individuales confirman los patrones que se aprecian en los censos generales. Cito aquí un censo realizado en 1759 en Corpus Christi, que muestra que las familias grandes fueron comunes, pero que también había un gran número de viudas y huérfanos. El resumen que sigue a continuación registra el tamaño de las familias o, en otras palabras, la cantidad de familias de dos personas, tres personas, etc., junto con la cantidad de gente en cada categoría de familias, y el total de huérfanos, viudas y viudos.

Estructura de la población de Corpus Christi en 1759

\begin{tabular}{|c|c|c|c|c|c|c|}
\hline $\begin{array}{c}\text { Tamaño } \\
\text { de la familia } \\
2\end{array}$ & $\begin{array}{c}\text { Cantidad } \\
\text { de familias } \\
314\end{array}$ & $\begin{array}{c}\text { Cantidad de personas } \\
\text { en esta categoría } \\
628\end{array}$ & Huérfanos & Huérfanas & Viudas & Viudos \\
\hline 3 & 211 & 633 & 137 & 137 & 122 & 6 \\
\hline 4 & 157 & 628 & & & & \\
\hline 5 & 153 & 765 & & & & \\
\hline 6 & 143 & 858 & & & & \\
\hline 7 & 58 & 406 & & & & \\
\hline 8 & 17 & 136 & & & & \\
\hline 9 & 8 & 72 & & & & \\
\hline
\end{tabular}

Fuente: "Matrícula deste pueblo de Corpus Christi”. 
Las misiones guaraníes tenían grandes cantidades de madres potenciales, lo que era un factor importante para la reproducción de la población. Además, el gran tamaño de las poblaciones también significa que aun con una fuerte mortalidad debida a las epidemias suficientes madres potenciales sobrevivieron. La cantidad de estas fue pequeña en las poblaciones en declive y hubo un desbalance de géneros, con más hombres que mujeres ${ }^{45}$. Por ejemplo, entre 1791 y 1832, los misioneros estacionados en la misión de Santa Cruz, en California, bautizaron 1.133 mujeres, cerca de la mitad de los bautismos. En 1832 la población de Santa Cruz era de 284, pero solo había 87 mujeres, menos de un tercio de la población. El desbalance de géneros fue inusual y esto explica el rápido declive de la población nativa. Simplemente no había suficientes mujeres en edad de tener hijos para neutralizar la alta mortalidad, particularmente la de niños y mujeres.

\section{Conclusiones}

En las primeras décadas, después del establecimiento de la primera misión en 1609, los establecimientos jesuitas en Paraguay atravesaron un período de inestabilidad y sufrieron los efectos de la cacería de esclavos de los paulistas. Sin embargo, después de la derrota de estos en Mbororé, en 1641, experimentaron algún crecimiento por reproducción natural. Aunque hubo una serie de epidemias, la población de las misiones se recuperó y creció. Entre 1641 y 1732 las cifras aumentaron desde 36.000 hasta 141.000. Las tasas de nacimiento y mortalidad muestran un lento o moderado crecimiento, incluso alto en algunos años, excepto durante los brotes epidémicos. Las tasas de mortalidad eran elevadas entre los niños, pero los nacimientos fueron consistentemente numerosos durante los años sin epidemias. La población guaraní creció considerablemente. En

Un pequeño fragmento de bautismos sobrevive para Santa Rosa en las décadas de 1750 y 1760, y muestra un gran número de nacimientos. La cifra de entierros de 1756 tomada del censo de ese año ubica la cantidad de bautismos en su contexto. En 1756 el crecimiento neto de la población de Santa Rosa fue de 67, sin contar la emigración.

Bautismos registrados en Santa Rosa, 1754-1763

\begin{tabular}{|l|c|c|}
\hline Año & Bautismos & Entierros \\
\hline 1754 & 176 & \\
\hline 1755 & 153 & \\
\hline 1756 & 180 & 113 \\
\hline 1757 & 185 & \\
\hline 1758 & 161 & \\
\hline 1759 & 168 & \\
\hline 1760 & 203 & \\
\hline 1761 & 190 & \\
\hline 1762 & 202 & \\
\hline 1763 & 183 & \\
\hline
\end{tabular}

Fuente: Registro de bautismos de Santa Rosa, Parroquia de Santa Rosa, Paraguay. Maeder, "Fuentes Jesuíticas de información demográfrica misional”.

45 Jackson, Indian Population Decline, 108-116. 
1768, el Rey Carlos III ordenó la expulsión de los jesuitas y estos fueron reemplazados por administradores civiles. Alguna diáspora se presentó, cuando los guaraníes dejaron las misiones para buscar trabajo o para escapar de la violencia y la destrucción de las guerras durante los primeros años del siglo XIX. Sin embargo, la dispersión no significó el fin de la población. Los guaraníes siguieron constituyendo una parte significativa de los habitantes de Paraguay, la Banda Oriental y las áreas circundantes.

Las tasas vitales de las poblaciones misioneras fueron similares a las de la Europa contemporánea, pero diferentes de las de otras fronteras en los márgenes de la América española. En contraste con las misiones guaraníes, las de baja California, California, el norte de Sonora y Texas decayeron. Muchos factores contribuyeron a esta decadencia. Por un lado, las misiones guaraníes tenían muchos más habitantes, y en varios momentos totalizaron más de 7.000. Las misiones de la frontera norte mexicana tendieron a ser pequeñas. En el caso de California, las más populosas tenían cerca de 2.700 habitantes. Hubo otras importantes diferencias. Las tasas de mortalidad tendieron a ser más altas que las de nacimiento, y la esperanza de vida, baja. Además de esto, como he señalado antes, hubo desbalances de género significativos, con más bajas cantidades de mujeres que de hombres. La causa de ello fue que las tasas de mortalidad fueron mayores en las mujeres que en los hombres, y por el tratamiento poco adecuado que se le daba al embarazo y los efectos de la sífilis, que se extendió en las poblaciones nativas y arruinó la salud de las mujeres y los niños por nacer. Mientras que los guaraníes sobrevivieron al período de las misiones como poblaciones viables, los nativos congregados en las misiones de la frontera norte mexicana, con varias excepciones, no lo hicieron. 


\section{Apéndice}

\section{Tabla 1}

\section{Población total de las misiones jesuitas de Paraguay}

\begin{tabular}{|l|c|c|c|c|c|}
\hline \multicolumn{1}{|c|}{ Año } & Población & Año & Población & Año & Población \\
\hline $1641 / 1643$ & 36,190 & 1724 & 117,164 & 1750 & 95,089 \\
\hline 1647 & 28.714 & 1732 & 141.242 & 1755 & 104.483 \\
\hline 1648 & 30.548 & 1733 & 128.389 & 1756 & 89.536 \\
\hline 1657 & 37.412 & 1734 & 116.250 & 1762 & 102.988 \\
\hline 1667 & 43.753 & 1735 & 108.228 & 1765 & 85.266 \\
\hline 1668 & 47.088 & 1736 & 102.721 & 1767 & 88.796 \\
\hline 1676 & 53.298 & 1737 & 104.473 & 1768 & 88.864 \\
\hline 1677 & 58.118 & 1738 & 90.287 & 1772 & 80.891 \\
\hline 1678 & 55.125 & 1739 & 81.159 & 1783 & 56.092 \\
\hline 1682 & 61.083 & 1740 & 73.910 & 1784 & 57.949 \\
\hline 1700 & 86.173 & 1741 & 76.960 & 1791 & 44.677 \\
\hline 1702 & 89.500 & 1742 & 78.929 & 1793 & 51.991 \\
\hline 1717 & 121.168 & 1743 & 81.355 & 1801 & 45.637 \\
\hline
\end{tabular}

Fuente: A. Huonder, “Reductions of Paraguay”, en The Catholic Enciclopedia (Nueva York: K. Knigth, 2003), enciclopedia en línea, obtenido de la red mundial el 24 de agosto de 2004, 12:00 horas. http: // www.newadvent.org/cathen/12688b.htm; Thomas Whigham, "Paraguay’s Pueblos”, 168; Édgar y Alfredo Poenitz, "Herencia misionera”, página web (Posadas, Argentina: TerritorioDigital.com, 2004), obtenido de la red mundial el 24 de agosto de 2004, 12:00 horas. http://www.herenciamisionera.com Maeder, "La población de las misiones", 49-80; Maeder, "Fuentes jesuíticas", 45-57. 
Tabla 2

Población de las misiones jesuitas de Paraguay, 1641-1682

\begin{tabular}{|l|c|c|c|c|c|c|}
\hline Misión & $\mathbf{1 6 4 1 / 1 6 4 3}$ & $\mathbf{1 6 4 7}$ & $\mathbf{1 6 5 7}$ & $\mathbf{1 6 6 7}$ & $\mathbf{1 6 7 6}$ & $\mathbf{1 6 8 2}$ \\
\hline Guasú & 998 & 1.150 & 1.327 & 1.940 & 2.326 & 2.741 \\
\hline Itapúa & 2.199 & 1.700 & 2.292 & 2.735 & 3.094 & 3.288 \\
\hline Candelaria & 1.490 & 1.077 & 1.471 & 2.363 & 1.991 & 1.868 \\
\hline S. Cosme & 2.100 & 1.075 & 1.376 & & 1.210 & 1.283 \\
\hline S. Ana & 850 & 779 & 1.024 & 1.300 & 1.352 & 1.415 \\
\hline Loreto & 1.476 & 1.700 & 1.920 & 2.089 & 2.358 & 2.772 \\
\hline S. I. Mini & 1.750 & 1.708 & 2.171 & 2.439 & 2.253 & 2.441 \\
\hline S. Carlos & 2.300 & 1.701 & 2.123 & 2.714 & 3.633 & 4.420 \\
\hline S. José & 1.441 & 1.334 & 1.268 & & & 2.272 \\
\hline Corpus Ch. & 1.604 & 1.300 & 1.331 & & & 1.350 \\
\hline Apóstoles & 1.635 & 1.144 & 3.239 & & 2.158 & 3.548 \\
\hline S. Nicolás & 1.803 & 1.854 & 3.684 & & 2.921 & 3.548 \\
\hline Concepción & 3.665 & 1.469 & 3.275 & & 6.035 & 7.014 \\
\hline S. Javier & 1.442 & 1.300 & 1.604 & & 2.740 & 3.029 \\
\hline La Mayor & 2.637 & 2.000 & 2.776 & & 4.378 & 5.171 \\
\hline Mártires & 1.040 & 1.186 & 1.278 & & 1.769 & 1.980 \\
\hline S. Miguel & 1.860 & 1.165 & 2.101 & & 3.830 & 3.740 \\
\hline La Cruz & 1.300 & 1.472 & 1.514 & & 2.212 & 2.251 \\
\hline San Tomé & 3.000 & 1.960 & 3.494 & & 5.129 & 5.243 \\
\hline Yapeyú & 1.600 & 1.600 & 1.828 & & 2.100 & 2.477 \\
\hline \hline
\end{tabular}

Fuente: Maeder, “La población de las misiones”, 49-80; Maeder, “Fuentes jesuíticas”, 45-57; Furlong, Misiones y sus pueblos, 175-179; Whigham, "Paraguay’s Pueblos”, 168; Pablo Hernández, S. J., Organización social de las doctrinas guaraníes de la Compañía de Jesús, 2 vols. (Barcelona, 1913), 2: 616-617. 
Tabla 3

Población de las misiones jesuitas de Paraguay, 1702-1744

\begin{tabular}{|c|c|c|c|c|c|c|c|c|c|c|c|}
\hline Misión & 702 & 1724 & 1731 & 1733 & 1735 & 1736 & 1738 & 1739 & 1740 & 1741 & 1744 \\
\hline Guasú & 700 & 343 & 195 & .266 & 631 & 1.576 & 1.846 & .964 & .018 & 2.152 & 2.231 \\
\hline $\mathrm{LaFe}$ & 739 & 5.463 & 515 & 4.251 & 465 & 2.595 & 2.701 & 2.903 & 3.086 & 3.298 & 3.593 \\
\hline S. Rosa & 000 & 4.742 & 6.093 & 2.775 & 1.780 & 1.671 & 1.828 & 1.916 & 1.973 & 2.031 & 2.170 \\
\hline Santiago & 842 & 2.720 & .524 & 3.479 & 3.237 & 3.740 & 3.955 & 4.081 & 4.128 & 4.276 & 4.389 \\
\hline Itapúa & 782 & 5.357 & 548 & 6.396 & 4.361 & 4.650 & 2.690 & 2.591 & 2.179 & 2.106 & 2.847 \\
\hline Candelaria & 596 & 2.863 & 3.317 & 3.134 & 2.990 & 3.048 & 1.511 & 1.503 & 1.441 & 1.639 & 1.764 \\
\hline S. Cosme & .573 & 2.120 & 2.306 & 2.145 & 2.143 & 1.531 & 1.225 & 1.236 & 1.209 & 1.094 & 1.272 \\
\hline S. Ana & 225 & 3.600 & 4.527 & 3.716 & 4.083 & 4.055 & 4.343 & 4.397 & 4.533 & 4.505 & 4.331 \\
\hline Loreto & 060 & 6.113 & 7.048 & 6.077 & 5.523 & 1.937 & 2.234 & 1.756 & 2.246 & 2.422 & 2.789 \\
\hline S. I. Mini & 2.000 & 3.138 & 4.356 & 3.959 & 3.010 & 1.808 & 1.934 & 1.849 & 1.933 & 2.076 & 2.218 \\
\hline Corpus Ch & 2.080 & 3.584 & 4.400 & 4.008 & 2.790 & 2.190 & 1.975 & 2.667 & 2.808 & 2.922 & 3.241 \\
\hline Trinidad & - & 3.140 & 3.569 & 3.598 & 1.829 & 1.733 & 1.975 & 2.149 & 2.268 & 2.047 & 2.245 \\
\hline Jesús & 018 & |ודט.1 & 2.436 & 2.241 & 2.256 & 2.204 & 1.902 & 1.962 & 1.050 & 1.850 & 1.679 \\
\hline S. Carlos & 355 & 065 & 388 & 3369 & 400 & 3.212 & .377 & 1.239 & 1.140 & .273 & 1.404 \\
\hline S. José & 594 & 3.274 & 3.720 & 3.605 & 3.473 & 3.382 & 1.392 & 1.338 & 1.390 & 1.411 & 1.594 \\
\hline Apóstoles & 530 & 140 & 185 & 5.267 & 3.884 & 3.716 & 1.315 & 1.341 & 1.494 & 1.582 & 1.577 \\
\hline Concepció & 553 & 894 & 848 & 5001 & 5.920 & 6.460 & 4.234 & 1.669 & 1.944 & .369 & 2.296 \\
\hline Mártires & 2.124 & 3.343 & 3.874 & 3.665 & 3.416 & 3.396 & 3.230 & 2.777 & 2.829 & 2.839 & 2.834 \\
\hline La Mayor & 2.869 & 3.490 & 3.902 & 3.585 & 2.903 & 2.232 & 2.262 & 711 & 819 & 894 & 993 \\
\hline S. Javier & 117 & 409 & 313 & (5) & 94 & 2.873 & 1.876 & 1.710 & 39 & 894 & 1.895 \\
\hline S. Nicolás & 4.090 & 6.667 & 7.690 & 7.415 & 6.986 & 6.104 & 5.071 & 1.772 & 2.194 & 2.279 & 3.107 \\
\hline S. Luis & 3.354 & 5.045 & 6.149 & 5.619 & 5.305 & 4.445 & 4.327 & 1.978 & 2.308 & 2.432 & 2.868 \\
\hline S. Lorenzo & 4.427 & 5.224 & 6.420 & 6.100 & 5.177 & 4.405 & 4.814 & 974 & 1.173 & 1.311 & 1.573 \\
\hline S. Miguel & 2.197 & 3.972 & 4.904 & 4.465 & 4.019 & 4.156 & 4.522 & 4.741 & 4.740 & 4.974 & 6.611 \\
\hline S. Juan & 2.650 & 4.629 & 4.503 & 4.968 & 4.621 & 5.110 & 5.012 & 4.949 & 2.171 & 2.525 & 2.843 \\
\hline Stos. Amg. & - & 4.052 & 4.601 & 4.925 & 4.501 & 4.336 & 4.921 & 5.163 & 5.228 & 5.199 & 4.824 \\
\hline San Tomé & 3.416 & 2.949 & 3.545 & 3.494 & 2.282 & 3.211 & 2.041 & 1.699 & 1.892 & 2.063 & 2.397 \\
\hline S. Borja & 2.600 & 2.906 & 3.629 & 3.658 & 3.584 & 3.358 & 2.998 & 3.244 & 3.291 & 3.430 & 3.814 \\
\hline La Cruz & 3.851 & 3.615 & 4.573 & 4.345 & 4.372 & 4.304 & 3.853 & 2.167 & 2.163 & 2.314 & 2.540 \\
\hline Yapeyú & 206 & 4.360 & 5.666 & 5.374 & 5.106 & 5.283 & 5.410 & 5.713 & 5.687 & 5.748 & 6.187 \\
\hline
\end{tabular}

Fuente: Maeder, “La población de las misiones”, 49-80; Maeder, “Fuentes jesuíticas”, 45-57; Furlong, Misiones y sus pueblos, 175-179; Whigham, "Paraguay’s Pueblos de Indios”, 168; Hernández, Organización social, 2:616-617. 
Tabla 4

Población de las misiones jesuitas de Paraguay, 1745-1785

\begin{tabular}{|c|c|c|c|c|c|c|c|c|c|c|c|c|}
\hline Misión & 1745 & 1750 & 1753 & 1756 & 1759 & 1764 & 1767 & 1768 & 1772 & 1777 & 1783 & 1785 \\
\hline Guasú & 2.238 & 2.251 & 2.167 & 2.472 & & \begin{tabular}{|l|}
3.139 \\
\end{tabular} & 2.100 & 1.916 & 1.655 & & 800 & 867 \\
\hline $\mathrm{La} \mathrm{Fe}$ & 3.796 & 4.296 & 4.240 & 4.853 & & 4.716 & 3.300 & 3.054 & 2.294 & & 723 & 1.062 \\
\hline S. Rosa & 2.215 & 2.524 & 2.455 & 3.056 & & 2.031 & 2.400 & 2.243 & 2.265 & & 1.266 & 1.264 \\
\hline Santiago & 4.484 & 3.968 & 4.633 & 4.304 & & 2.712 & 3.600 & 2.822 & 3.585 & & 1.119 & 1.215 \\
\hline Itapúa & 2.969 & 3.276 & 3.518 & 3.789 & & 4.308 & 4.600 & 4.784 & 4.505 & & 3.037 & 2.889 \\
\hline Candelaria & 1.814 & 2.031 & 2.017 & 2.409 & & 2.817 & 3.600 & 3.064 & 3.077 & & 1.513 & 1.748 \\
\hline S. Cosme & 1.325 & 1.449 & 1.422 & 1.632 & & 2.206 & 3.300 & 2.337 & 1.709 & & 1.103 & 1.111 \\
\hline S. Ana & 4.214 & 4.778 & 4.787 & 5.040 & 5.191 & 4.001 & 4.400 & 4.334 & 5.645 & & 1.834 & 1.747 \\
\hline Loreto & 2.855 & 3.276 & 3.195 & 4.023 & & 4.937 & 3.200 & 2.462 & 2.492 & & 1.472 & 1.457 \\
\hline S. I. Mini & 2.297 & 2.520 & 2.623 & 2.773 & 4.135 & 3.074 & 3.100 & 3.306 & 3.738 & & 1.021 & 798 \\
\hline Corpus Ch. & 3.364 & 3.976 & 3.800 & 4.773 & 4.642 & 4.280 & 4.000 & 4.587 & 4.887 & 4.121 & 2.727 & 2.574 \\
\hline Trinidad & 2.484 & 2.629 & 2.623 & 2.680 & & 2.946 & 2.600 & 2.365 & 1.477 & & 1.101 & 1.097 \\
\hline Jesús & 1.722 & 1.899 & 1.856 & 2.074 & & 2.361 & 2.900 & 2.286 & 2.392 & & 1.306 & 1.302 \\
\hline S. Carlos & 1.595 & 1.663 & 1.678 & 2.024 & & 2.191 & & 2.377 & 1.968 & & 977 & \\
\hline S. José & 1.669 & 2.019 & 1.889 & 2.310 & & 1.955 & & 2.122 & 2.180 & & 1.007 & \\
\hline Apóstoles & 1.728 & 2.118 & 1.923 & 2.522 & & 1.993 & & 2.127 & 2.277 & & 1.571 & \\
\hline Concepción & 2.192 & 2.136 & 2.274 & 2.912 & & 2.724 & & 1.475 & 2.935 & & 1.950 & \\
\hline Mártires & 2.847 & 3.112 & 2.981 & 3.217 & & 2.220 & & 1.662 & 1.724 & & 1.197 & \\
\hline La Mayor & 1.823 & 2.128 & 2.682 & 2.870 & & 1.228 & & 2.839 & 1.398 & & 978 & \\
\hline S. Javier & 1.905 & 1.968 & 1.942 & 1.898 & & 1.724 & & 1.527 & 1.655 & & 1.379 & \\
\hline S. Nicolás & 3.530 & 4.255 & 4.245 & 416 & & 3.925 & & 4.194 & 3.741 & & 3.667 & \\
\hline S. Luis & 2.968 & 3.037 & 4.245 & 3.828 & & 3.575 & & 3.500 & 3.420 & & 3.500 & \\
\hline S. Lorenzo & 1.563 & 1.729 & 1.838 & 1.459 & & 1.173 & & 1.412 & 1.454 & & 1.273 & \\
\hline S. Miguel & 6.675 & 6.635 & 6.898 & 1.035 & & 2.726 & & 3.556 & 2.118 & & 1.973 & \\
\hline S. Juan & 2.925 & 3.221 & 3.228 & 3.347 & & 3.805 & & 4.106 & 3.087 & & 2.338 & \\
\hline Stos. Amg. & 4.818 & 5.186 & 5.105 & 2.531 & & 3.112 & & 2.820 & 2.039 & & 1.926 & \\
\hline San Tomé & 2.498 & 2.917 & 2.709 & 3.042 & & 2.511 & & 2.172 & 2.317 & & 1.837 & \\
\hline S. Borja & 3.924 & 3.435 & 3.493 & 1.668 & & 2.893 & & 2.761 & 2.131 & & 2.906 & \\
\hline La Cruz & 2.656 & 2.518 & 2.575 & 2.982 & & 3.568 & & 3.243 & 3.402 & & 3.746 & \\
\hline Yapeyú & 6.147 & 6.518 & 6.726 & 7.597 & & 7.501 & & 7.974 & 3.322 & & 4.747 & \\
\hline
\end{tabular}

Fuente: Maeder, “La población de las misiones”, 49-80; Maeder, “Fuentes jesuíticas”, 45-57; Furlong, Misiones y sus pueblos, 175-179; Whigham, "Paraguay’s Pueblos de Indios”, 168; Hernández, Organización social, 2: 616-617; "Empadronamiento de las Treinta Pueblos de Misiones, por el Coronel Don Marcos de Larrazabal”, 1772. Archivo General de la Nación, Buenos Aires, Empadronamiento de Misiones, Sala 9-188-4; Édgar y Alfredo Poenitz, Misiones, provincia guaranítica: Defensa y disolución (Posadas, 1993), 54-55; Pablo Pastells, S. J., Historia de la Compañía de Jesús de la provincia de Paraguay (Madrid: Instituto Santo Toribio Megroviejo, 1956), 8: 118; Catálogo de la Numeración de las Doctrinas, MG 592, Benson Latin American Collection, General Libraries of the University of Texas at Austin. 
Tabla 5

Población de las misiones jesuitas de Paraguay, 1793-1802

\begin{tabular}{|l|r|r|r|}
\hline \multicolumn{1}{|c|}{ Misión } & $\mathbf{1 7 9 3}$ & $\mathbf{1 8 0 1}$ & $\mathbf{1 8 0 2}$ \\
\hline Guasú & 1.354 & 712 & 891 \\
\hline La Fe & 809 & 1.233 & 1.113 \\
\hline S. Rosa & 1.910 & 1.261 & 1.193 \\
\hline Santiago & 1.412 & 1.262 & 1.322 \\
\hline Itapúa & 2.066 & 2.131 & 1.789 \\
\hline Candelaria & 1.490 & 1.343 & 1.334 \\
\hline S. Cosme & 1.550 & 860 & 850 \\
\hline S. Ana & 1.454 & 1.293 & 1.464 \\
\hline Loreto & 1.261 & 1.164 & 1.046 \\
\hline S. I. Mini & 664 & 906 & 921 \\
\hline Corpus Ch. & 1.946 & 2.335 & 2.443 \\
\hline Trinidad & 997 & 877 & 851 \\
\hline Jesús & 1.066 & 1.036 & 700 \\
\hline S. Carlos & 1.023 & 1.013 & 1.010 \\
\hline S. José & 1.086 & 865 & 803 \\
\hline Apóstoles & 2.052 & 1.914 & 1.058 \\
\hline Concepción & 1.349 & 1.127 & 975 \\
\hline Mártires & 892 & 708 & 605 \\
\hline La Mayor & 690 & 559 & 573 \\
\hline S. Javier & 895 & 959 & 1.036 \\
\hline S. Nicolás & 2.984 & 2.406 & \\
\hline S. Luis & 3.312 & 2.776 & \\
\hline S. Lorenzo & 1.171 & 1.037 & \\
\hline S. Miguel & 2.334 & 1.664 & \\
\hline S. Juan & 2.018 & 1.292 & 1.0969 \\
\hline Stos. Amg. & 1.448 & 1.786 & \\
\hline San Tomé & 1.433 & 2.413 & \\
\hline S. Borja & 2.154 & 3.238 & \\
\hline La Cruz & 3.871 & & \\
\hline Yapeyú & & & \\
\hline \hline
\end{tabular}

Fuente: Maeder, “La población de las misiones”, 49-80; Maeder, “Fuentes jesuíticas”, 45-57; Furlong, Misiones y sus pueblos, 175-179; Whigham, "Paraguay’s Pueblos de Indios”, 168; Hernández, Organización social, 2: 616-617; "Empadronamiento de las Treinta Pueblos”, 1772. "Empadronamiento de Misiones”, Archivo General; Poenitz, Misiones, 54-55. 


\section{Tabla 6}

Tasas brutas de nacimiento (TBN) y mortalidad (TBM) por mil habitantes en 1733 y 1736

\begin{tabular}{|c|c|c|c|c|}
\hline Misión & 1733TBN* & 1733ТВМ* & 1736TBN & 1736TВM \\
\hline Guasú & 49,5 & 56,5 & 35,3 & 33,5 \\
\hline $\mathrm{LaFe}$ & 86,1 & 40,7 & 49,5 & 28,8 \\
\hline S. Rosa & 76,2 & 49,1 & 55,6 & 44,9 \\
\hline Santiago & 33,1 & 22,5 & 48,2 & 36,8 \\
\hline Itapúa & 53,3 & 18,9 & 50,0 & 43,8 \\
\hline Candelaria & 43,2 & 53,2 & 45,5 & 50,2 \\
\hline S. Cosme & 46,9 & 15,4 & 28,9 & 100,8 \\
\hline S. Ana & 55,3 & 26,2 & 33,8 & 79,6 \\
\hline Loreto & 92,8 & 31,3 & 25,2 & 239,2 \\
\hline S. I. Mini & 84,9 & 39,3 & 24,6 & 169,8 \\
\hline Corpus & 69,4 & 25,1 & 28,0 & 88,2 \\
\hline Trinidad & 43,7 & 50,3 & 45,9 & 72,2 \\
\hline Jesús & 56,8 & 121,1 & 47,0 & 57,6 \\
\hline S. Carlos & 44,5 & 70,8 & 62,1 & 74,6 \\
\hline S. José & 43,4 & 93,7 & 38,3 & 84,1 \\
\hline Apóstoles & 27,2 & 60,0 & 58,7 & 41,5 \\
\hline Concepción & 41,1 & 55,5 & 48,1 & 47,3 \\
\hline Mártires & 51,2 & 124,2 & 55,0 & 58,3 \\
\hline La Mayor & 48,6 & 133,3 & 33,1 & 91,3 \\
\hline S. Javier & 33,1 & 115,5 & 42,1 & 94,2 \\
\hline S. Nicolás & 64,1 & 103,5 & 32,9 & 103,9 \\
\hline S. Luis & 42,5 & 148,9 & 35,6 & 56,7 \\
\hline S. Lorenzo & 36,3 & 99,9 & 34,2 & 50,0 \\
\hline S. Miguel & 30,1 & 110,4 & 53,0 & 32,4 \\
\hline S. Juan & 42,1 & 94,7 & 39,4 & 43,5 \\
\hline Stos. Amg. & 38,3 & 66,3 & 44,7 & 48,7 \\
\hline San Tomé & 63,3 & 57,6 & 56,1 & 54,8 \\
\hline S. Borja & 38,0 & 92,8 & 56,1 & 49,1 \\
\hline La Cruz & 52,8 & 174,5 & 73,2 & 47,1 \\
\hline Yapeyú & 56,4 & 126,8 & 96,0 & 40,5 \\
\hline
\end{tabular}

*Estimadas.

Fuente: Censos anuales individuales de las misiones jesuitas de los años 1724, 1733, 1736, 1739, 1740, 1741, 1744 y 1745, titulados “Catálogo de la numeración anual de las doctrinas del río Paraná” y "Catálogo de la numeración anual de las doctrinas del río Uruguay”, Archivo General de la Nación, Buenos Aires; Maeder, “Fuentes jesuíticas”, 45-57. 
Tabla 7

Tasas brutas de nacimiento (TBN) y mortalidad (TBM) por mil habitantes en 1739 y 1740

\begin{tabular}{|l|c|c|c|c|}
\hline \multicolumn{1}{|c|}{ Misión } & $\mathbf{1 7 3 9 T B N}$ & $\mathbf{1 7 3 9 T B M}$ & $\mathbf{1 7 4 0 T B N}$ & $\mathbf{1 7 4 0 T B M}$ \\
\hline Guasú & 84,5 & 47,7 & 68,2 & 56,5 \\
\hline La Fe & 106,5 & 53,3 & 86,1 & 40,7 \\
\hline S. Rosa & 68,9 & 44,9 & 76,2 & 49,1 \\
\hline Santiago & 51,2 & 24,3 & 33,1 & 22,5 \\
\hline Itapúa & 52,0 & 97,4 & 53,3 & 18.9 \\
\hline Candelaria & 96,6 & 52,3 & 43,2 & 53,2 \\
\hline S. Cosme & 32,7 & 37,6 & 46,9 & 15,4 \\
\hline S. Ana & 60,8 & 28,3 & 55,3 & 26,2 \\
\hline Loreto & 63,6 & 30,0 & 92,8 & 31,3 \\
\hline S. I. Mini & 58,4 & 118,0 & 84,9 & 39,3 \\
\hline Corpus Ch. & 73,6 & 28,9 & 69,4 & 25,1 \\
\hline Trinidad & 53,7 & 115,4 & 43,7 & 50,3 \\
\hline Jesús & 81,5 & 50,0 & 49,4 & 31,6 \\
\hline S. Carlos & 11,4 & 12,2 & 88,0 & 32,3 \\
\hline S. José & 29,5 & 47,4 & 86,7 & 20,9 \\
\hline Apóstoles & 26,6 & 25,1 & 79,1 & 22,4 \\
\hline Concepción & 7,1 & 35,0 & 64,1 & 27,0 \\
\hline Mártires & 40,9 & 184,2 & 61,2 & 34,2 \\
\hline La Mayor & 39,6 & 565,4 & 85,8 & 23,9 \\
\hline S. Javier & 34,7 & 37,3 & 74,3 & 22,2 \\
\hline S. Nicolás & 10,7 & 336,8 & 120,8 & 50,2 \\
\hline S. Luis & 20,3 & 565,1 & 87,0 & 36,0 \\
\hline S. Lorenzo & 33,2 & 556,9 & 46,2 & 50,3 \\
\hline S. Miguel & 47,8 & 32,3 & 52,9 & 20,3 \\
\hline S. Juan & 64,5 & 75,0 & 14,4 & 485,0 \\
\hline Stos. Amg. & 52,4 & 52,4 & 46,3 & 27,1 \\
\hline San Tomé & 230,8 & 113,6 & 19,4 \\
\hline S. Borja & 43,0 & 58,3 & 21,0 \\
\hline La Cruz & 416,6 & 88,1 & 85,8 \\
\hline Yapeyú & 38,5 & 68,8 & 37,5 \\
\hline
\end{tabular}

Fuente: Censos anuales individuales de las misiones jesuitas de los años 1724, 1733, 1736, 1739, 1740, 1741, 1744 y 1745, titulados “Catálogo... del río Paraná” y “Catálogo... del río Uruguay”, Archivo General; Maeder, "Fuentes jesuíticas”, 45-57. 
Tabla 8

Tasas brutas de nacimiento (TBN) y mortalidad (TBM) por mil habitantes en 1741 y 1745

\begin{tabular}{|l|c|c|c|c|}
\hline \multicolumn{1}{|c|}{ Misión } & $\mathbf{1 7 4 1 C B R}$ & $\mathbf{1 7 4 1 C D R}$ & $\mathbf{1 7 4 5 C B R}$ & $\mathbf{1 7 4 5 C D R}$ \\
\hline Guasú & 112,5 & 54,0 & 73,1 & 72,6 \\
\hline La Fe & 109,9 & 40,8 & 98,3 & 39,5 \\
\hline S. Rosa & 93,3 & 59,3 & 84,3 & 41,5 \\
\hline Santiago & 54,0 & 24,5 & 59,0 & 24,4 \\
\hline Itapúa & 67,5 & 45,4 & 75,2 & 48,5 \\
\hline Candelaria & 49,3 & 68,0 & 86,7 & 53,9 \\
\hline S. Cosme & 51,3 & 31,4 & 65,3 & 36,2 \\
\hline S. Ana & 74,1 & 57,1 & 55,7 & 24,5 \\
\hline Loreto & 93,1 & 50,8 & 69,9 & 36,9 \\
\hline S. I. Mini & 93,1 & 82,8 & 85,7 & 71,2 \\
\hline Corpus Ch. & 97,2 & 55,6 & 78,1 & 11,7 \\
\hline Trinidad & 54,7 & 46,3 & 66,4 & 47,2 \\
\hline Jesús & 75,1 & 77,3 & 66,7 & 45,9 \\
\hline S. Carlos & 62,3 & 24,6 & 78,4 & 47,7 \\
\hline S. José & 48,2 & 38,9 & 75,9 & 32,6 \\
\hline Apóstoles & 52,2 & 34,8 & 67,9 & 43,8 \\
\hline Concepción & 52,5 & 26,8 & 44,0 & 24,4 \\
\hline Mártires & 67,9 & 56,6 & 60,0 & 49,8 \\
\hline La Mayor & 95,2 & 40,3 & 144,0 & 64,5 \\
\hline S. Javier & 63,7 & 31,9 & 64,4 & 39,6 \\
\hline S. Nicolás & 83,9 & 36,9 & 95,9 & 83,7 \\
\hline S. Luis & 70,2 & 27,7 & 71,8 & 49,5 \\
\hline S. Lorenzo & 60,5 & 27,3 & 89,0 & 45,8 \\
\hline S. Miguel & 63,3 & 25,7 & 50,8 & 40,4 \\
\hline S. Juan & 108,7 & 31,3 & 60,1 & 25,0 \\
\hline Stos. Amg. & 56,4 & 37,9 & 60,9 & 60,0 \\
\hline San Tomé & 27,0 & 78,9 & 30,0 \\
\hline S. Borja & 24,6 & 53,8 & 65,8 \\
\hline La Cruz & 20,7 & 68,9 & 43,7 \\
\hline Yapeyú & 35,6 & 70,6 & 50,6 \\
\hline
\end{tabular}

Fuente: Censos anuales individuales de las misiones jesuitas de los años 1724, 1733, 1736, 1739, 1740, 1741, 1744 y 1745, titulados “Catálogo... del río Paraná” y “Catálogo... del río Uruguay”, Archivo General; Maeder, "Fuentes jesuíticas”, 45-57. 


\section{Tabla 9}

Tasas brutas de nacimiento (TBN) y mortalidad (TBM) por mil habitantes en las misiones guaraníes, 1691-1766

\begin{tabular}{|c|c|c|c|c|c|}
\hline Año & TBN & TBM & Año & TBN & TBM \\
\hline 1691 & 60 & 34 & 1747 & 70 & 43 \\
\hline 1694 & 65 & 40 & 1748 & 66 & 43 \\
\hline 1707 & 65 & 50 & 1749 & 71 & 84 \\
\hline 1708 & 73 & 47 & 1750 & 71 & 40 \\
\hline 1729 & 68 & 38 & 1751 & 65 & 43 \\
\hline 1732 & 55 & 48 & 1752 & 60 & 40 \\
\hline 1733 & 41 & 133 & 1753 & 63 & 35 \\
\hline 1736 & 46 & 72 & 1754 & 65 & 41 \\
\hline 1737 & 47 & 26 & 1755 & 66 & 42 \\
\hline 1738 & 44 & 172 & 1756 & 47 & 40 \\
\hline 1739 & 38 & 140 & 1758 & 53 & 54 \\
\hline 1740 & 61 & 61 & 1762 & 51 & 47 \\
\hline 1741 & 77 & 43 & 1763 & 48 & 60 \\
\hline 1742 & 71 & 55 & 1764 & 51 & 135 \\
\hline 1743 & 76 & 45 & 1765 & 45 & 92 \\
\hline 1744 & 71 & 43 & 1766 & 52 & 47 \\
\hline 1745 & 70 & 44 & & & \\
\hline 1746 & 74 & 45 & & & \\
\hline
\end{tabular}

Fuente: Maeder, “Fuentes jesuíticas”. 
Tabla 10

Porcentaje de mujeres con respecto a la población total en las misiones jesuitas de Paraguay en 1724, 1733, 1739 y 1745

\begin{tabular}{|l|c|c|c|c|}
\hline \multicolumn{1}{|c|}{ Misión } & $\mathbf{1 7 2 4}$ & $\mathbf{1 7 3 3}$ & $\mathbf{1 7 3 9}$ & $\mathbf{1 7 4 5}$ \\
\hline Guasú & 49,4 & 49,6 & 55,3 & 54,1 \\
\hline La Fe & 51,4 & 43,9 & 38,3 & 51,3 \\
\hline S. Rosa & 50,0 & 54,5 & 55,0 & 51,8 \\
\hline Santiago & 50,3 & 49,4 & 49,6 & 48,8 \\
\hline Itapúa & 58,1 & 54,4 & 55,5 & 53,8 \\
\hline Candelaria & 55,1 & 55,2 & 54,2 & 55.1 \\
\hline S. Cosme & 53,0 & 53,4 & 54,4 & 53,1 \\
\hline S. Ana & 51,2 & 52,2 & 43,0 & 49,8 \\
\hline Loreto & 53,1 & 49,9 & 52,0 & 52,3 \\
\hline S. I. Mini & 52,1 & 50,6 & 57,3 & 54,4 \\
\hline Corpus Ch. & 52,2 & 50,9 & 52,2 & 51,3 \\
\hline Trinidad & 54,6 & 53,1 & 55,1 & 50,3 \\
\hline Jesús & 51,5 & 51,5 & 49,0 & 49,4 \\
\hline S. Carlos & 55,7 & 58,7 & 61,0 & 55,7 \\
\hline S. José & 54,7 & 53,3 & 55,7 & 54,5 \\
\hline Apóstoles & 50,9 & 53,1 & 55,7 & 54,5 \\
\hline Concepción & 63,7 & 52,1 & 49,7 & 52,4 \\
\hline Mártires & 45,0 & 53,1 & 51,9 & 51,6 \\
\hline La Mayor & 52,7 & 52,4 & 54,5 & 52,2 \\
\hline S. Javier & 52,7 & 52,4 & 56,9 & 55,0 \\
\hline S. Nicolás & 52,1 & 52,5 & 57,6 & 54,0 \\
\hline S. Luis & 53,3 & 50,8 & 53,8 & 53,0 \\
\hline S. Lorenzo & 52.4 & 52,1 & 50.1 & 51,9 \\
\hline S. Miguel & 51,4 & 51,1 & 45,9 & 50,5 \\
\hline S. Juan & 52,1 & 51,5 & 54,4 & 50,7 \\
\hline Stos. Amg. & 49,4 & 51,6 & 49,9 & 51,3 \\
\hline San Tomé & 68,1 & 56,3 & 57,0 & 53,6 \\
\hline S. Borja & 53,8 & 57,0 & 55,1 & 55,7 \\
\hline La Cruz & 55,5 & 53,3 & 53,9 & 54,4 \\
\hline Yapeyú & 53,8 & 52,4 & 61,8 & 51,5 \\
\hline
\end{tabular}

Fuente: “Catálogo... del río Paraná/del río Uruguay año 1724”, Archivo Nacional, Asunción, Paraguay; “Catálogo... río Paraná/del Río Uruguay año 1733”, Archivo General; “Catálogo... del río Paraná/del río Uruguay año 1739”, Archivo General; “Catálogo... río Paraná/del río Uruguay año 1745”, Archivo General. 
Tabla 11

Entierros en las misiones guaraníes en 1733, 1736, 1739 y 1740

\begin{tabular}{|c|c|c|c|c|c|c|c|c|}
\hline \multirow[b]{2}{*}{ Misión } & \multicolumn{2}{|c|}{1733} & \multicolumn{2}{|c|}{1736} & \multicolumn{2}{|c|}{1739} & \multicolumn{2}{|c|}{1740} \\
\hline & Adultos & Párvulos & Adultos & Párvulos & Adultos & Párvulos & Adultos & Párvulos \\
\hline Guasú & 560 & 632 & 50 & 40 & 22 & 66 & 27 & 84 \\
\hline $\mathrm{LaFe}$ & 1.365 & 1.253 & 58 & 13 & 46 & 98 & 36 & 83 \\
\hline S. Rosa & 900 & 1.363 & 43 & 37 & 26 & 56 & 30 & 64 \\
\hline Santiago & 76 & 131 & 58 & 61 & 38 & 57 & 37 & 55 \\
\hline Itapúa & 243 & 568 & 89 & 102 & 98 & 164 & 18 & 31 \\
\hline Candelaria & 52 & 194 & 49 & 101 & 13 & 66 & 10 & 70 \\
\hline S. Cosme & 80 & 182 & 117 & 99 & 32 & 14 & 5 & 14 \\
\hline S.Ana & 377 & 471 & 151 & 174 & 35 & 89 & 31 & 84 \\
\hline Loreto & 515 & 471 & 779 & 542 & 17 & 50 & 11 & 44 \\
\hline S. I. Mini & 192 & 257 & 275 & 236 & 148 & 80 & 15 & 54 \\
\hline Corpus Ch. & 324 & 261 & 161 & 95 & 20 & 52 & 20 & 47 \\
\hline Trinidad & 138 & 204 & 68 & 64 & 143 & 85 & 48 & 60 \\
\hline Jesús & 136 & 154 & 66 & 64 & 50 & 45 & 20 & 42 \\
\hline S. Carlos & 44 & 201 & 68 & 111 & 6 & 23 & 8 & 32 \\
\hline S. José & 117 & 249 & 167 & 125 & 19 & 47 & 9 & 19 \\
\hline Apóstoles & 149 & 178 & 92 & 69 & 15 & 18 & 5 & 25 \\
\hline Concepción & 102 & 229 & 90 & 190 & 102 & 46 & 7 & 38 \\
\hline Mártires & 154 & 337 & 72 & 127 & 388 & 207 & 40 & 55 \\
\hline La Mayor & 223 & 298 & 133 & 132 & 1.047 & 232 & 6 & 11 \\
\hline S. Javier & 172 & 289 & 166 & 163 & 22 & 48 & 14 & 24 \\
\hline S. Nicolás & 204 & 595 & 362 & 364 & 1.050 & 658 & 58 & 31 \\
\hline S. Luis & 218 & 718 & 163 & 138 & 1.457 & 988 & 37 & 34 \\
\hline S. Lorenzo & 400 & 371 & 119 & 140 & 1.655 & 1.026 & 31 & 18 \\
\hline S. Miguel & 240 & 296 & 50 & 80 & 68 & 78 & 43 & 53 \\
\hline S. Juan & 226 & 272 & 49 & 152 & 241 & 135 & 1.502 & 898 \\
\hline Stos. Amg. & 129 & 207 & 117 & 102 & 137 & 121 & 66 & 74 \\
\hline San Tomé & 60 & 140 & 54 & 71 & 332 & 139 & 13 & 20 \\
\hline S. Borja & 124 & 235 & 97 & 79 & 76 & 35 & 25 & 63 \\
\hline La Cruz & 246 & 617 & 77 & 129 & 1.086 & 519 & 81 & 105 \\
\hline Yapeyú & 174 & 559 & 38 & 169 & 45 & 163 & 52 & 162 \\
\hline
\end{tabular}

Fuentes: “Enumeratio Annua, 1733”, Archivo General de la Nación, Buenos Aires, Sala lX-6-9-6; “Enumeratio Annua, 1736”, Archivo General, Sala 1X-6-9-7; “Catálogo... del río Paraná año 1736”; “Numeración... del río Uruguay año de 1736”; “Catálogo... del río Paraná año 1740”; “Numeración... del río Uruguay año de 1740”, Archivo Nacional; Hernández, Organización social, 2:616-617. 
Tabla 12

Disminución neta de la población

\begin{tabular}{|c|c|c|c|c|}
\hline Misión & 1733 & 1736 & 1739 & 1740 \\
\hline Guasú & -1.076 & 5 & 68 & 23 \\
\hline $\mathrm{LaFe}$ & -2.472 & 51 & 143 & 131 \\
\hline S. Rosa & -2.153 & 19 & 44 & 52 \\
\hline Santiago & -86 & 37 & 107 & 43 \\
\hline Itapúa & -604 & 27 & -122 & 89 \\
\hline Candelaria & -50 & -14 & 67 & -15 \\
\hline S. Cosme & -192 & -154 & -6 & 39 \\
\hline S. Ana & -758 & -187 & 140 & 128 \\
\hline Loreto & -723 & -1.182 & 75 & 108 \\
\hline S. I. Mini & -247 & -437 & -115 & 88 \\
\hline Corpus Ch. & -306 & -178 & 111 & 118 \\
\hline Trinidad & -227 & -48 & -122 & -14 \\
\hline Jesús & -154 & -24 & 60 & 35 \\
\hline S. Carlos & -91 & -30 & -2 & 69 \\
\hline S. José & -201 & -159 & -25 & 88 \\
\hline Apóstoles & -179 & 67 & 2 & 76 \\
\hline Concepción & -86 & 5 & -118 & 62 \\
\hline Mártires & -289 & -11 & -463 & 75 \\
\hline La Mayor & -323 & -169 & -1.235 & 44 \\
\hline S. Javier & -329 & -182 & -5 & 89 \\
\hline S. Nicolás & -304 & -496 & -1.654 & 125 \\
\hline S. Luis & -669 & -112 & -2.357 & 101 \\
\hline S. Lorenzo & -491 & -82 & -2.521 & -4 \\
\hline S. Miguel & -150 & 83 & 70 & 155 \\
\hline S. Juan & -289 & -19 & -53 & -2329 \\
\hline Stos. Amg. & -142 & -18 & 0 & 99 \\
\hline San Tomé & 20 & 3 & -309 & 160 \\
\hline S. Borja & -212 & 25 & 13 & 101 \\
\hline La Cruz & -602 & 114 & -1.540 & 5 \\
\hline Yapeyú & -407 & 283 & 191 & 179 \\
\hline
\end{tabular}

Un examen detallado de las tasas vitales de dos misiones, Loreto y San Lorenzo, nos brinda información adicional sobre el efecto de las epidemias en la población misione- 
ra en la década de 1730 (Tabla 7). Antes de la primera epidemia, en 1724, la misión de Loreto contaba con una población de 6.113 habitantes, y en 6.077 con 1733, al final del primer brote. Las cifras bajan a 1.756 en 1739, pero luego crecen durante las siguientes dos décadas, y alcanzan 4.023 en 1756. Las tasas brutas de los años en que no hubo epidemias se mantuvieron en un promedio de 36 por mil habitantes, es decir, que el 3,6\% de la población murió cada año. Dos años evidencian una crisis en la mortalidad, al multiplicarse por más de tres la tasa normal. La tasa bruta de 1733 fue de 146,3 por mil, casi cuatro veces la mortalidad normal. En 1736 la tasa fue de 239,2, lo que significa 6,6 veces la normal. Las tasas brutas de natalidad fueron moderadas y altas, excepto en los años con severas crisis de mortalidad. En 1738, por ejemplo, la tasa bruta de nacimiento fue de 23,4, mucho más baja que en los años en que no hubo epidemias. El tamaño promedio de la familia, una medida bruta de su tamaño, bajó durante la década y alcanzó 3,6 en 1739.

La población de San Lorenzo experimentó una drástica disminución durante la década y solo empezó a recuperarse en la época de la llamada Guerra Guaraní, a mediados de la década de 1750. En 1731 la misión tenía una población de 6.420 habitantes, pero bajó a 974 en 1739. Luego se recuperó lentamente en las siguientes décadas, alcanzando 1.563 habitantes en 1745 y 1.459 en 1756. Las tasas brutas de mortalidad tuvieron un promedio de 44,2 en los años en que no hubo epidemias, y las dos documentadas representaron crisis de extrema mortalidad, especialmente en 1739. En 1733 la tasa bruta de mortalidad fue de 117 por mil habitantes, o sea 2,7 veces la normal. La mortalidad en 1739 fue extremadamente alta, con una tasa bruta de 557, es decir, 12,6 veces normal. El año de 1739 debió ser infernal para los residentes de San Lorenzo. La población de la misión había mostrado signos de recuperación en los años posteriores a los primeros brotes, alcanzando 4.814 habitantes a finales de 1738 . Cuando las viruelas se diseminaron en la comunidad, 1.655 adultos y 1.026 niños pequeños murieron. Solamente quedaron 974 personas al final del año, reflejando la mortalidad y una pérdida neta de 2.521 habitantes, teniendo en cuenta a los guaraníes que huyeron para no tener una horrible muerte. La tasa bruta de mortalidad indica que el 55,7\% de la población falleció. Varias de las misiones vecinas tuvieron tasas igualmente altas. En San Luis Gonzaga hubo 2.445 entierros en 1739 y una tasa bruta de mortalidad de 565,1 por mil habitantes; en San Nicolás, 1.708 entierros y una tasa de 336,8; en Santa María La Mayor, 1.279 entierros y una tasa de 565,4, y en La Cruz, 1.605 entierros con una tasa de 416,6. Al año siguiente murieron 2.400 personas en San Juan Bautista, con una tasa de 484,9. Las tasas de nacimiento en San Lorenzo fueron moderadas y altas en los años que siguieron a la epidemia, pero la recuperación fue lenta, como se señaló anteriormente. 
Tabla 13

Tasas vitales de las misiones de Loreto y San Lorenzo en años seleccionados

Loreto

\begin{tabular}{|c|c|c|r|r|r|r|r|c|}
\hline Año & Población & Familias & Bautismos & Entierros & TBN & TBM & $\begin{array}{c}\text { Tamaño } \\
\text { promedio de } \\
\text { las familias }\end{array}$ & Año \\
\hline 1702 & 4.060 & 1.048 & 321 & 224 & $81,0^{*}$ & $56,5^{*}$ & 3,9 & 1702 \\
\hline 1724 & 6.113 & 1.543 & 380 & 165 & $64,4^{*}$ & $28^{*}$ & 4,0 & 1724 \\
\hline 1733 & 6.077 & 1.484 & 263 & 986 & $38,7^{*}$ & $145^{*}$ & 4,1 & 1733 \\
\hline 1736 & 1.937 & 543 & 139 & 1.321 & 32,5 & 308,4 & 3,6 & 1736 \\
\hline 1739 & 1.756 & 496 & 142 & 67 & 63,6 & 30 & 3,5 & 1739 \\
\hline 1740 & 2.246 & 560 & 163 & 55 & 92,8 & 31,3 & 4,0 & 1740 \\
\hline 1741 & 2.422 & 635 & 209 & 114 & 93,1 & 50,8 & 3,8 & 1741 \\
\hline 1744 & 2.789 & 703 & 246 & 122 & $92,3^{*}$ & $45,8^{*}$ & 4,0 & 1744 \\
\hline 1745 & 2.855 & 738 & 195 & 103 & 69,9 & 36,9 & 3,9 & 1745 \\
\hline 1756 & 4.023 & 853 & 216 & 115 & $55,1^{*}$ & $29,3^{*}$ & 4,7 & 1756 \\
\hline
\end{tabular}

San Lorenzo

Entierros

\begin{tabular}{|c|c|c|c|c|c|c|c|c|}
\hline Año & Familias & Población & Bautismos & Adultos & Párvulos & TBN & TBM & $\begin{array}{l}\text { Tamaño } \\
\text { promedio de } \\
\text { las familias }\end{array}$ \\
\hline 1690 & 823 & 3.512 & 84 & 27 & 36 & N/A & N/A & 4.3 \\
\hline 1694 & 896 & 3.769 & 258 & 19 & 79 & $71,5^{*}$ & $27,2 *$ & 4.2 \\
\hline 1698 & 953 & 4.140 & 131 & 35 & 87 & $31,7^{*}$ & $29,5 *$ & 4.3 \\
\hline 1702 & 990 & 4.427 & 262 & 46 & 105 & $56,8^{*}$ & $35,1^{*}$ & 4.5 \\
\hline 1705 & 1.027 & 4.544 & 196 & 40 & 110 & $43,6^{*}$ & $33,4^{*}$ & 4.4 \\
\hline 1707 & 1.022 & 4.519 & 283 & 25 & 106 & $64,8 *$ & $30 *$ & 4.4 \\
\hline 1724 & 1.246 & 5.224 & 423 & 63 & 173 & $84^{*}$ & $46,9 *$ & 4.2 \\
\hline 1733 & 1.359 & 6.100 & 280 & 400 & 371 & $42,5 *$ & $117^{*}$ & 4.5 \\
\hline 1736 & 899 & 4.405 & 177 & 119 & 140 & 34,2 & 50 & 4.9 \\
\hline 1739 & 165 & 974 & 160 & 1.655 & 1.026 & 33,2 & 557 & 5.9 \\
\hline 1740 & 242 & 1.173 & 45 & 31 & 18 & 46,2 & 50,3 & 4.9 \\
\hline 1741 & 340 & 1.311 & 71 & 12 & 20 & 60,5 & 27,3 & 3.9 \\
\hline 1744 & 429 & 1.573 & 121 & 8 & 50 & $80,1^{*}$ & 38,4 & 3.7 \\
\hline 1745 & 464 & 1.563 & 140 & 28 & 54 & 89 & 52,1 & 3.4 \\
\hline 1756 & 358 & 1.459 & 80 & 23 & 82 & $53,9 *$ & 70,8 & 4.1 \\
\hline 1764 & 258 & 1.173 & 62 & 198 & 138 & $42,9 *$ & $232,2^{*}$ & 4.6 \\
\hline
\end{tabular}

* Estimado.

Fuentes: Censos anuales individuales de las misiones jesuitas de los años 1724, 1733, 1736, 1739, 1740, 1741, 1744 y 1745, titulados “Catálogo... del río Paraná”; “Catálogo... del río Uruguay”, Archivo General; Maeder, "Fuentes jesuíticas”, 45-57; Aurelio Porto, Historia das Missoes Orientais do Uruguai (Porto Alegre, 1952), 70; “Catálogo... del río Paraná”, “Catálogo... río Uruguay”, Manuel Gondra Collection, MG 592, Benson Latin American Collection, General Libraries of the University of Texas, Austin. 


\section{Bibliografía}

\section{Fuentes primarias}

Archivo General de la Nación, Buenos Aires, Argentina.

Archivo Nacional, Asunción, Paraguay.

Benson Latin American Collection, General Libraries of the University of Texas at Austin.

Registros Bautismales y de Entierros de San Francisco de Borja, Diócesis de Uruguaiana, Uruguaina, Brasil.

\section{Fuentes secundarias}

Alvarez Kern, Arno, ed. Arqueologia Historica Missioneira. Porto Alegre: Edipucrs, 1998.

Blumers, Teresa. La contabilidad en las reducciones guaraníes. Asunción, 1992.

Carbonell de Masy, Rafael. Estrategias de desarrollo rural en los pueblos Guaraníes (1609-1767). Barcelona: Instituto de Cooperación Iberoamericana, 1992.

, Teresa Blumers y Norberto Lveinton. La reducción jesuítica de Santos Cosme y Damián: Su historia, su economía y su arquitectura (16331797). Asunción, 2003.

Flinn, Michael. The European Demographic System, 1520-1820. Baltimore, 1980.

Flores, Moacyr. Reduçoes Jesuíticas dos Guaranis. Porto Alegre: Edipucrs, 1997.

Furlong Cardiff, Guillermo, S. J. Misiones y sus pueblos de guaraníes. Buenos Aires, 1962.

Ganson, Barbara. The Guarani Under Spanish Rule in the Río de la Plata. Stanford: Stanford University Press, 2003.

González Rissotto, Luis Rodolfo. "La importancia de las misiones jesuíticas en la formación de la sociedad uruguaya”. Estudios Ibero-Americanos 15, núm. 1 (junio 1989): 191-214.

Hernández, Pablo, S. J. Organización social de las doctrinas guaraníes de la Compañía de Jesús. 2 vols. Barcelona, 1913. 
Huonder, A. "Reductions of Paraguay”. En The Catholic Enciclopedia. Nueva York: K. Knigth, 2003. Enciclopedia en línea. Obtenido de la red mundial el 24 de agosto de 2004. 12:00 horas. http://www.newadvent.org/cathen/12688b.htm.

Jackson, Robert H. “The 1781-1782 Smallpox Epidemic in Baja California”. Journal of California and Great Basin Anthropology 3 (verano 1981): 138-143.

. "Causes of Indian Depopulation in the Pimeria Alta Missions of Northern Sonora”. Journal of Arizona History 24 (1983): 405-429.

. Indian Population Decline: The Missions of Northwestern New Spain, 16871840. Albuquerque, 1994.

. Regional Markets and Agrarian Transformation in Bolivia: Cochabamba, 1539-1960. Albuquerque, 1995.

Maeder, Ernesto. “La población de las misiones de guaraníes (1641-1682). Reubicación de los pueblos y consecuencias demográficas”. Estudios Ibero-Americanos 15, núm. 1 (junio 1989): 49-80.

- Misiones del Paraguay: Conflictos y disolución de la sociedad guaraní (1768-1850). Madrid: Mapfre, 1992.

. "Fuentes jesuíticas de información demográfica misional para los siglos XVII y XVIII”. En Fuentes útiles para los estudios de la población Americana. Simposio del $49^{\circ}$ Congreso Internacional de Americanistas, Quito 1997, coord. Dora Celton, 45-57. Quito: Abya-Yala, 1997.

Owens, David. "A Historical Geography of the Indian Missions in the Jesuit Province of Paraguay, 1609-1768”. Tesis doctoral, University of Kansas, Kansas, 1977.

Pastells, Pablo, S. J. Historia de la Compañía de Jesús de la provincia de Paraguay. Madrid: Instituto Santo Toribio Megroviejo, 1956.

Poenitz, Édgar y Alfredo. Misiones, provincia guaranítica: Defensa y disolución. Posadas, 1993.

. "Herencia misionera”. Página web. Posadas, Argentina: TerritorioDigital.com, 2004. Obtenido de la red mundial el 24 de agosto de 2004, 12:00 horas. http:/ /www.herenciamisionera.com.ar

Porto, Aurelio. Historia das Missoes Orientais do Uruguai. Porto Alegre, 1952. 
Reff, Daniel T. Disease, depopulation, and culture change in northwestern New Spain, 1518-1764. Salt Lake City, 1991.

. "The Jesuit Mission Frontier in Comparative Perspective: The Reductions of the Río de la Plata and the Missions of Northwestern Mexico, 15881700". En Contested Ground: Comparative Frontiers on the Northern and Southern Edges of the Spanish Empire, eds. Donna Guy y Thomas Sheridan, 16-31. Tucson, 1998.

Sarreal, Julia. "Paraguay Missions: Illusions of Prosperity and Decay, 1700-1800”. Ponencia presentada en la reunión anual de la Conference on Latin American History, Washington, D.C., 9 de enero 2004.

Whigham, Thomas. "Paraguay's Pueblos de Indios: Echoes of a Missionary Past”. En The New Latin American Mission History. eds. Erick Langer y Robert H. Jackson. Lincoln, 1995.

Fecha de presentación: 1 de enero de 2004.

Fecha de aceptación: 24 de agosto de 2004. 